\title{
Intact polar lipids in the water column of the eastern tropical North Pacific: abundance and structural variety of non-phosphorus lipids
}

\author{
Florence Schubotz ${ }^{1}$, Sitan Xie ${ }^{1, \text { a }}$, Julius S. Lipp ${ }^{1}$, Kai-Uwe Hinrichs ${ }^{1}$, and Stuart G. Wakeham ${ }^{2}$ \\ ${ }^{1}$ MARUM and Department of Geosciences, University of Bremen, 28359 Bremen, Germany \\ ${ }^{2}$ Skidaway Institute of Oceanography, Savannah, GA 31411, USA \\ ${ }^{a}$ current address: Wai Gao Qiao Free Trade Zone, 200131 Shanghai, China
}

Correspondence: Florence Schubotz (schubotz@uni-bremen.de)

Received: 6 March 2018 - Discussion started: 13 March 2018

Revised: 16 October 2018 - Accepted: 17 October 2018 - Published: 6 November 2018

\begin{abstract}
Intact polar lipids (IPLs) are the main building blocks of cellular membranes and contain chemotaxonomic, ecophysiological and metabolic information, making them valuable biomarkers in microbial ecology and biogeochemistry. This study investigates IPLs in suspended particulate matter (SPM) in the water column of the eastern tropical North Pacific Ocean (ETNP), one of the most extensive open-ocean oxygen minimum zones (OMZs) in the world, with strong gradients of nutrients, temperature and redox conditions. A wide structural variety in polar lipid headgroup composition and core structures exists along physical and geochemical gradients within the water column, from the oxygenated photic zone to the aphotic OMZ. We use this structural diversity in IPLs to evaluate the ecology and ecophysiological adaptations that affect organisms inhabiting the water column, especially the mid-depth OMZ in the context of biogeochemical cycles. Diacylglycerol phospholipids are present at all depths, but exhibit the highest relative abundance and compositional variety (including mixed acyl/ether core structures) in the upper and core OMZ where prokaryotic biomass was enriched. Surface ocean SPM is dominated by diacylglycerol glycolipids that are found in photosynthetic membranes. These and other glycolipids with varying core structures composed of ceramides and hydroxylated fatty acids are also detected with varying relative abundances in the OMZ and deep oxycline, signifying additional non-phototrophic bacterial sources for these lipids. Betaine lipids (with zero or multiple hydroxylations in the core structures) that are typically assigned to microalgae are found throughout the water column down to the deep oxycline but do not show a depth-related trend in rela-
\end{abstract}

tive abundance. Archaeal IPLs comprised of glycosidic and mixed glycosidic-phosphatidic glycerol dibiphytanyl glycerol tetraethers (GDGTs) are most abundant in the upper OMZ, where nitrate maxima point to ammonium oxidation but increase in relative abundance in the core OMZ and deep oxycline. The presence of non-phosphorus "substitute" lipids within the OMZ suggest that the indigenous microbes might be phosphorus limited ( $\mathrm{P}$ starved) at ambient phosphate concentrations of 1 to $3.5 \mu \mathrm{M}$, although specific microbial sources for many of these lipids still remain unknown.

\section{Introduction}

Oxygen minimum zones (OMZs) are permanently oxygendeficient regions in the ocean defined by $\mathrm{O}_{2}$ concentrations $<20 \mu \mathrm{M}$. They occur in areas where the coastal or openocean upwelling of cold, nutrient-rich waters drive elevated levels of primary production and the subsequent respiration of organic matter exported out of productive surface waters consume oxygen faster than it is replaced by ventilation or by mid-depth lateral injections of oxygenated water. Low oxygen levels cause habitat compression, whereby species intolerant to low levels of oxygen are restricted to oxygenated surface water (Keeling et al., 2010; Rush et al., 2012). But even these low levels of oxygen permit the vertical migration of some zooplankton taxa into hypoxic waters (e.g., Seibel, 2011; Wishner et al., 2013). Oxygen depletion stimulates diverse microbial life capable of utilizing alternative electron acceptors for respiration under microaerobic conditions (e.g., Ulloa et al., 2012; Tiano et al., 2014; Carolan et al., 2015; 
Kalvelage et al., 2015). Important prokaryote-mediated processes within OMZs include denitrification and the anaerobic oxidation of ammonium (anammox), which together may account for $30 \%-50 \%$ of the total nitrogen loss from the ocean to the atmosphere (Gruber, 2008; Lam and Kuypers, 2011). Modern day OMZs comprise $\sim 8 \%$ of global ocean volume (Karstensen et al., 2008; Paulmier and Ruiz-Pino, 2009; Lam and Kuypers, 2011), but any expansion in the coming decades as a consequence of global warming and increased stratification (Stramma et al., 2008; Keeling et al., 2010) would have profound effects on marine ecology, oceanic productivity, global carbon and nitrogen cycles, the biological pump and sequestration of carbon (Karstensen et al., 2008; Stramma et al., 2010; Wright et al., 2012). A better understanding of the effect of low $\mathrm{O}_{2}$ on marine biogeochemistry and microbial ecology is thus warranted.

The eastern tropical North Pacific Ocean (ETNP), situated off the western coast of Mexico and Central America, hosts one of the largest OMZs in the open ocean, extending halfway across the Pacific Ocean and comprising 41\% of global OMZs (Lavín and Fiedler, 2006; Fiedler and Talley, 2006; Paulmier and Ruiz-Pino, 2009). By comparison, OMZs of the eastern tropical South Pacific Ocean off Peru and Chile and in the Arabian Sea are $\sim 14 \%$ and $\sim 8 \%$, respectively, of global OMZs. In the ETNP, a sharp permanent pycnocline develops where warm, saline surface waters lie on top of a shallow thermocline, producing a highly stratified water column. Moderate primary production, dominated by picoplankton, depends on oceanic upwelling and the wind mixing of coastal waters but is generally limited by the lack of micronutrient-dissolved iron (Franck et al., 2005; Pennington et al., 2006). Remineralization, $\sim 70 \%$ of which is microbially mediated (Cavan et al., 2016) from particulate organic carbon exported out of surface waters consume oxygen at rates that cannot be balanced by ventilation across the pycnocline and by sluggish lateral circulation, leading to $\mathrm{O}_{2}$ levels $<2 \mu \mathrm{M}$ at depths between $\sim 100$ and $\sim 800 \mathrm{~m}$. Abundances of micro- (Olson and Daly, 2014) and macrozooplankton (Wishner et al., 2013; Williams et al., 2014) that are high in surface waters are reduced in the OMZ, and those macrozooplankton that are diel vertical migrators survive in the OMZ with reduced metabolic rates (Maas et al., 2014; Cass and Daly, 2015). Microbial abundances and activities for both heterotrophic and chemoautotrophic metabolisms are high in both surface waters and within the OMZ, but they again have reduced metabolic rates in the OMZ (Podlaska et al., 2012). A strong nutricline indicates microbial nitrogen cycling involving co-occurring nitrification, denitrification and anammox (Rush et al., 2012; Podlaska et al., 2012), perhaps contributing up to $45 \%$ of the global pelagic denitrification (Codispoti and Richards, 1976). Microbial communities are mainly comprised of proteobacteria, with increasing contributions of archaea in deeper waters. Yet, on average, ca. $50 \%$ of the prokaryotic communities within the
OMZ of the ETNP remained without characterization (Podlaska et al., 2012).

Intact polar lipids (IPLs) are the main building blocks of cellular membranes and may be used to characterize the abundance and physiology of aquatic microorganisms from all three domains of life. IPLs represent a diverse range of molecular structures, including phosphatidyl, glycosidic, phospho-glycosidic, and amino acid polar head groups linked to glyceryl-acyl and glyceryl-O-alkyl apolar moieties. IPL distributions have been documented in surface waters of the eastern subtropical South Pacific (Van Mooy and Fredricks, 2010), the western North Atlantic Ocean (Van Mooy et al., 2006, 2009; Popendorf et al., 2011a), the South Pacific Ocean (Kharbush et al., 2016), the Mediterranean Sea (Popendorf et al., 2011b), the North Sea (Brandsma et al., 2012), lakes (Bale et al., 2016), the western English Channel (White et al., 2015) and throughout the water columns of stratified water bodies (Ertefai et al., 2008; Schubotz et al., 2009; Wakeham et al., 2012; Pitcher et al., 2011; Xie et al., 2014; Basse et al., 2014; Sollai et al., 2015). Surface waters are typically dominated by nine IPL classes. Three diacylglycerol glycolipids, monoglycosyl (1G-), diglycosyl (2G) and sulfoquinovosyl diacylglycerol (SQ-DAG), are main IPLs found in all thylakoid membranes of phototrophs, including those of cyanobacteria (Siegenthaler et al., 1998) ${ }^{1}$. Three betaine lipids, diacylglyceryl homoserine (DGTS), hydroxymethyl-trimethyl- $\beta$-alanine (DGTA) and carboxy-Nhydroxymethyl-choline (DGCC), are also generally abundant. Betaine lipids are widely distributed in lower plants and green algae (Dembitsky, 1996) and are thus usually assigned to eukaryotic algae in the ocean (Popendorf et al., 2011a), but DGTS was recently also found in bacteria where phosphorus is limited (Yao et al., 2015; Sebastian et al., 2016). Three commonly detected phospholipids are diacylglycerol phosphatidyl choline (PC-DAG, often simply referred to elsewhere as PC), phosphatidyl ethanolamine (PE-DAG, often PE), and phosphatidyl glycerol (PG-DAG, often PG), all of which have mixed eukaryotic or bacterial sources in the upper water column (Sohlenkamp et al., 2003; Popendorf et al., 2011a). Microbial source assignments have been broadly confirmed by isotope labeling studies (Popendorf et al., 2011a). In oxygen-deficient subsurface waters, IPL distributions are more diverse, and other phospholipids such as diacylglycerol phosphatidyl- $N$-methylethanolamine (PME-DAG), phosphatidyl- $N, N$-dimethylethanolamine (PDME-DAG) and diphosphatidylglycerol (DPG) increase in abundance; these

\footnotetext{
${ }^{1}$ Elsewhere in the literature 1G-DAG, 2G-DAG and SQ-DAG are also termed MGDG, DGDG and SQDG. However, we have opted to retain the 1G-DAG nomenclature, 2-DAG nomenclature, etc., as other IPLs discussed throughout also contain monoglycosyland diglycosyl-moieties (e.g., 1G-GDGT and 2G-GDGT). Likewise, we retain the nomenclature PC-DAG, PE-DAG and PG-DAG for phospholipids elsewhere termed PC, PE and PG.
} 
IPLs occur in a number of bacteria that may inhabit lowoxygen environments (Schubotz et al., 2009; Wakeham et al., 2012). Diether glycerol phospholipids and glycosidic ceramides with unidentified sources have also been detected (Schubotz et al., 2009; Wakeham et al., 2012), and the latter have been recently observed to be abundant in phosphoruslimited diatoms (Hunter et al., 2018). IPLs that are unique to marine archaea are comprised of glycerol dialkyl glycerol tetraether (GDGT) core lipids with various glycosidic, diglycosidic and mixed phospho-glyco polar head groups (e.g., Schouten et al., 2008; Pitcher et al., 2011; Zhu et al., 2016; Elling et al., 2017). Abundances of archaeal IPGDGTs vary considerably with depth but are typically elevated in zones of water column oxygen depletion, especially where ammonium-oxidizing thaumarchaeota are abundant (Pitcher et al., 2011; Schouten et al., 2012; Sollai et al., 2015).

IPL can also be indicators of metabolic and physiologic status. Many organisms remodel their IPL composition when faced with environmental stressors such as changes in $\mathrm{pH}$, salinity, temperature or availability of nutrients (Zhang and Rock, 2008; Van Mooy et al., 2009; Meador et al., 2014; Carini et al., 2015; Elling et al., 2015). Replacing phospholipids with non-phosphorus-containing substitute lipids is an important mechanism when facing nutrient phosphate starvation in oligotrophic surface waters where phosphate concentrations may be as low as nanomolar levels. Cyanobacteria replace PG-DAG with SQ-DAG (Benning et al., 1993; Van Mooy et al., 2006), and microalgae and some bacteria replace PC-DAG with DGTS (Geiger et al., 1999; Van Mooy et al., 2009; Popendorf et al., 2011b) due to their similar ionic charge at a physiological $\mathrm{pH}$. Heterotrophic marine bacteria can replace PE-DAG with either 1G-DAG or DGTS (Carini et al., 2015; Sebastian et al., 2016; Yao et al., 2015). Notably, substitute lipids are also biosynthesized under micromolar concentrations of phosphate (Bosak et al., 2016).

Here, we use IPL distributions in suspended particulate matter (SPM) to characterize eukaryotic, bacterial and archaeal communities inhabiting the water column of the ETNP. This study is an extension of that of Xie et al. (2014), which focused on the distribution of core and intact polar archaeal and bacterial tetraether lipids at two of the stations investigated here (Stations 1 and 8). The water column of the ETNP comprises distinct biogeochemical zones based on oxygen concentrations, and IPL distributions reflect the localized ecology. Abundant non-phosphorus substitute lipids within the core of the OMZ suggest that the source microorganisms are phosphorus limited, even at micromolar concentrations of phosphate. Overall our results provide deeper insight into the broad community composition and the physiologic state of microorganisms inhabiting OMZs.

\section{Methods}

\subsection{Sample collection and CTD data}

Suspended particulate matter (SPM) samples were collected at four stations (distance to shore between 400 $600 \mathrm{~km}$; Fig. 1) along a northwest-southeast transect (Station 1: $13^{\circ} 01.87^{\prime} \mathrm{N}, 104^{\circ} 99.83^{\prime} \mathrm{W}$; Station 2 : $11^{\circ} 99.96^{\prime} \mathrm{N}$, $101^{\circ} 22.82^{\prime} \mathrm{W}$; Station 5: $10^{\circ} 68.94^{\prime} \mathrm{N}, 96^{\circ} 34.12^{\prime} \mathrm{W}$; and Station 8: $\left.8^{\circ} 99.46^{\prime} \mathrm{N}, 90^{\circ} 00.18^{\prime} \mathrm{W}\right)$ in the ETNP during the R/V Seward Johnson cruise in November 2007 (R/V Seward Johnson Cruise Scientists, 2007). Station 1 in the Tehuantepec Bowl is an area of relatively low primary productivity (e.g., $0.05 \mathrm{mg} \mathrm{Chl} a \mathrm{~m}^{-2}$; Fiedler and Talley, 2006; Pennington et al., 2006), whereas Station 8 in the Costa Rica Dome is moderately productive ( $1 \mathrm{mg} \mathrm{Chl} a \mathrm{~m}^{-2}$ ). All stations are characterized by a strong thermocline/pycnocline/oxycline (at 20-50 m depths, depending on location) and a profound and thick OMZ (down to $\sim 2 \mu \mathrm{MO}_{2}$ between $\sim 300-800 \mathrm{~m}$ depth). Station 1 is a reoccupation of the Vertical Transport and Exchange II and III site from the early 1980's (Lee and Cronin, 1984; Martin et al., 1987; Wakeham and Canuel, 1988; Wakeham, 1987, 1989).

Seawater was filtered in situ using submersible pumps (McLane Research Laboratories WTS-142 filtration systems) deployed on the conducting cable of the conductivity, temperature and depth (CTD) rosette that measured temperature, conductivity, oxygen, fluorescence or chlorophyll $a$, and transmissivity during pump deployments and during pumping. Filtered water volumes ranged between 130 and 1800 L (Table S1 in the Supplement). Pumps were fitted with two-tier $142 \mathrm{~mm}$ diameter filter holders: a $53 \mu \mathrm{m}$ mesh Nitex "prefiltration" screen to remove larger eukaryotes and marine snow aggregates, and a double-stacked tier of ashed glass fiber filters ( $142 \mathrm{~mm}$ Gelman type A/E, nominal pore size $0.7 \mu \mathrm{m})$. The IPL concentrations we report represent minimum values to reflect the potentially inefficient collection of $0.7 \mu \mathrm{m}$ particles by GFFs. Since the pore size of the filters may also decrease during filtration the recovered material may vary depending on filtration time. Following pump recovery, GFF filters and Nitex screens were wrapped in precombusted foil and stored frozen at $-20^{\circ} \mathrm{C}$ until extraction.

\subsection{Elemental, pigment and nutrient analysis}

Particulate organic carbon (POC) and total particulate nitrogen (TN) were measured on $14 \mathrm{~mm}$-diameter subsamples of each glass fiber filter (GFF) prior to lipid extraction; therefore, the POC and TN concentrations reported here are only for $<53 \mu \mathrm{m}$ material. The plugs were acidified in $\mathrm{HCl}$ vapor in a desiccator for $12 \mathrm{~h}$ to remove inorganic carbon. Elemental analysis was performed with a ThermoFinnigan Flash EA Series 1112 interfaced with a ThermoFinnigan Delta V isotope ratio mass spectrometer at the Skidaway Institute Scientific Stable Isotope Laboratory. Organic carbon and nitrogen 


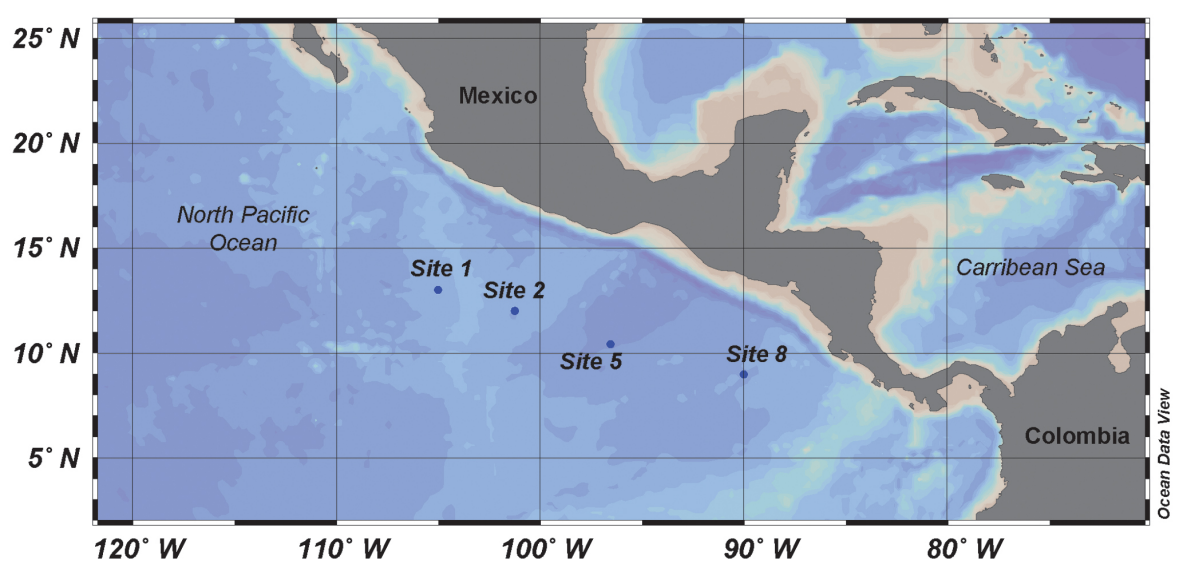

Figure 1. Map of ETNP with the R/V Seward Johnson (November 2007) cruise sampling stations investigated in this study.

contents were calibrated against internal laboratory chitin powder standards, which in turn had previously been crosscalibrated against USGS 40 and 41 international standards.

Chlorophyll $a(\mathrm{Chl} a)$ and pheopigment concentrations were measured on board the ship (Olson and Daly, 2014). Seawater samples $(100-500 \mathrm{ml})$ from CTD casts were filtered onto Whatman GF/F filters $(0.7 \mu \mathrm{m})$, which were immediately extracted with $90 \%$ acetone. Fluorescence was measured with a Turner Designs $10 \mathrm{AU}$ fluorometer, and Chl $a$ concentrations were determined after Parsons et al. (1984). The post-cruise HPLC analysis of pigments in $100-500 \mathrm{ml}$ seawater samples filtered onto Whatman GF/F $(0.7 \mu \mathrm{m})$ filters were conducted at the College of Charleston Grice Marine Laboratory, Charleston, South Carolina, on a Hewlett Packard 1050 system (DiTullio and Geesey, 2002).

Seawater samples for nutrient analyses $\left(\mathrm{NO}_{2}^{-}, \mathrm{NO}_{3}^{-2}\right.$, $\mathrm{NH}_{4}^{+}$and $\mathrm{PO}_{4}^{3-}$ ) were collected directly from Niskin bottles into acid-washed, $30 \mathrm{~mL}$ high-density polyethylene (HDP) bottles. After three rinses, bottles were filled to the shoulder, sealed and frozen $\left(-20^{\circ} \mathrm{C}\right)$. All frozen samples were transported to the Oceanic Nutrient Laboratory at the University of South Florida (USF) for analysis using a Technicon Autoanalyzer II.

\subsection{Lipid extraction and analysis of intact polar lipids}

Lipids associated with the $<53 \mu \mathrm{m}$ SPM on the GFFs were Soxhlet extracted shortly after the expedition in 2008 using dichloromethane: methanol (DCM: $\mathrm{MeOH} ; 9: 1 v / v$ ) for $8 \mathrm{~h}$. Extracted lipids were partitioned into DCM against $5 \% \mathrm{NaCl}$ solution and dried over $\mathrm{Na}_{2} \mathrm{SO}_{4}$. Total lipid extracts (TLEs) were stored at $-20^{\circ} \mathrm{C}$. Soxhlet extractions, rather than, for example, microwave-assisted Bligh-Dyer extractions, were chosen at the time, because they were the only feasible way to handle the double $142 \mathrm{~mm}$ filters. Extraction protocol can surely affect IPL distributions, as shown by Lengger et al. (2012) for smaller sediment samples.
IPL analyses by high-performance liquid chromatography coupled with mass spectrometry (HPLC-MS) were carried out initially in 2010-2011 and again in 2015 as instrument protocols improved. In between these analyses we did not observe a notable selective loss of IPL compounds; instead we were able to detect a much larger suite of IPL structures due to improved detection and chromatographic separation techniques (Wörmer et al., 2013). The confidence in these results is supported by the analysis of IPL standards (Table S2) that are stored at $-20^{\circ} \mathrm{C}$ over several years (fresh standard mixtures are typically prepared every 2 to 3 years), which do not indicate the degradation of any particular IPL over time (Fig. S1). The analyses in 2010-2011 focused on determining absolute concentrations of the major IPLs (for distinction between major and minor IPLs, see results section). Aliquots of the TLE were dissolved in $\mathrm{DCM} /$ methanol $(5: 1 v / v)$ for injection in a ThermoFinnigan Surveyor HPLC system coupled to a ThermoFinnigan LCQ DecaXP Plus Ion Trap mass spectrometer (MS) via electrospray interface (HPLC-ESI-IT-MS ${ }^{n}$ ), using conditions described previously (Sturt et al., 2004; Xie et al., 2014). Ten $\mu \mathrm{L}$ of a known TLE aliquot, spiked with $\mathrm{C}_{19}-\mathrm{PC}$ as the internal standard, was injected onto a LiChrospher Diol-100 column $(150 \times 2.1 \mathrm{~mm}, 5 \mu \mathrm{m}$, Alltech, Germany) equipped with a guard column of the same packing material. Absolute IPL concentrations were determined in the positive ionization mode with automated data-dependent fragmentation of the two most abundant base-peak ions. Acyl moieties of glycolipids and aminolipids were identified via HPLC-IT-ESI$\mathrm{MS}^{2}$ experiments in positive ionization mode, whereas phospholipid side-chain composition was analyzed in the negative ionization mode. Details of mass spectral interpretation and the identification of fatty-acid moieties are described in Sturt et al. (2004) and Schubotz et al. (2009) and are exemplified in Table S3. HPLC-MS analysis is not able to differentiate between double bonds or rings; therefore in the subsequent text we will refer to double bond equivalents (DBE) 
to include both possibilities. Similarly absolute chain length cannot be determined as branched, and straight chain alkyl chains cannot be differentiated; therefore we report total carbon atom numbers for the alkyl side chains. The assignment of the betaine lipid DGTS was according to the retention time of the commercially available standard DGTS (Avanti Polar Lipids, USA). The isomer DGTA, which elutes at a different retention time due to its structural difference (e.g., Brandsma et al., 2012), was not observed in the HPLC-MS chromatograms. For all analyses, response factors of individual IPLs relative to the injection standard $\mathrm{C}_{19}$-PC were determined using dilution series of commercially available standards (Table S2).

Subsequent analyses in 2015 were used to obtain sum formulas and IPL structures based on exact masses in the MS1 and MS-MS experiments and to additionally provide data on minor lipids, which were below the detection limit during the 2010-2011 ion trap analyses (for distinction between major and minor lipids, see results section). For the 2015 measurements absolute quantities could not be determined, since the TLE had been used for other experiments, and the information on TLE amounts used was unknown; therefore, these analyses are used to describe relative abundances. Analyses were performed on a Bruker maXis Plus ultrahigh-resolution quadrupole time-of-flight mass spectrometer (Q-TOF) with an electrospray ionization (ESI) source coupled to Dionex Ultimate 3000RS ultra-high-pressure liquid chromatography (UHPLC). Separation of IPLs was achieved using a Waters Acquity UPLC BEH Amide column as described in Wörmer et al. (2013), which resulted in better chromatographic separation of compounds and higher sensitivity compared to the 2010-2011 analyses. Peak areas in extracted mass chromatograms were corrected with absolute response factors determined in dilution series of commercially available standards (Table S2). Some ions assigned to either PE-AEG and PC-AEG could not be quantified individually due to the co-elution of these compounds and were thus quantified as one group using the mean response factor of PE- and PC-DAG. For compound classes for which no standards were available, (e.g., PI-DAG, OL and the unknown aminolipids AL-I and AL-II), the relative responses could not be corrected for. Assuming that these compounds may ionize similarly as structurally related IPLs, values may be off by a factor of 0.2 to 1.4 , which is the maximum range of response factors observed for the standards.

\subsection{Statistical analysis}

Non-metric multidimensional scaling (NMDS) analysis was used to illustrate the relationships among objects hidden in a complex data matrix (Rabinowitz, 1975) and was performed in the free software $\mathrm{R}$ (version 3.4.3, https://www.r-project. org/, last access: 5 March 2018) with metaMDS (vegan library, version 2.4-6), as described by Wakeham et al. (2012). The datasets of relative lipid distribution and variations in carbon number and double bond equivalents were standardized by Hellinger transformation using the function decostand, while for all other variables (environmental parameters, microbial groups), absolute numbers were used. The compositional dissimilarity was calculated by Euclidean distance measure. The resulting plot shows the distribution of lipids and sampling depths. Microbial groups and geochemical parameters were overlaid by function envfit. Lower stress is related to the high quality of the solution, and stress values $\leq 0.1$ indicate results of good quality (Rabinowitz, 1975). A non-parametric Spearman's rank order correlation analysis was performed on combined data from environmental variables and IPL ratios and IPL relative abundances of all four stations using SigmaPlot 11.0 (Systat Software Inc., San Jose, California, USA).

\section{Results}

\subsection{Biogeochemical setting}

All along the transect, the thin mixed layer (upper $\sim 20 \mathrm{~m}$ ) was warm, $\sim 25-28^{\circ} \mathrm{C}$, with oxygen concentrations approaching air saturation at $\sim 200 \mu \mathrm{M}$ (Fig. 2). The euphotic zone ( $1 \%$ of surface photosynthetically active radiation) generally ranged between 50 and $80 \mathrm{~m}$ depth. The thermocline was abrupt at $\sim 20-50 \mathrm{~m}$, where temperatures dropped to $\sim$ $15-18^{\circ} \mathrm{C}$ and oxygen decreased to $\sim 20 \mu \mathrm{M}$. Temperatures stabilized by $\sim 250-300 \mathrm{~m}$ depth at $\sim 10-12^{\circ} \mathrm{C}$ and oxygen levels were $<2 \mu \mathrm{M}$; especially at Station 8 there were spatially and temporally variable oxygen intrusions into the upper portion of the OMZ. By 600-800 m depth, a deep oxycline was observed where oxygen concentrations began to rise again to $\sim 40 \mu \mathrm{M}$ at temperatures of $\sim 4{ }^{\circ} \mathrm{C}$ by $1250 \mathrm{~m}$. For the purposes of this discussion, the water column of the ETNP was partitioned into four horizons based on oxygen content: an oxic epipelagic zone down to the thermocline $\left(0-50 \mathrm{~m} ; 200 \mu \mathrm{M}>\mathrm{O}_{2}>20 \mu \mathrm{M}\right)$, an upper OMZ (Station 1 and 8: 50-300 m, Station 5: 50-350 $\mathrm{m}$ and Station 2: 50$200 \mathrm{~m} ; 20 \mu \mathrm{M}>\mathrm{O}_{2}>2 \mu \mathrm{M}$ ), the core OMZ (Station 1 and 8: 300-800 m, Station 5: 350-600 m and Station 2: 200-600 m; $\mathrm{O}_{2}<2 \mu \mathrm{M}$ ), and a deep oxycline (Station 1 and $8 \geq 800 \mathrm{~m}$ and Station 2 and $5 \geq 600 \mathrm{~m} ; \mathrm{O}_{2}>2 \mu \mathrm{M}$ ) of rising $\mathrm{O}_{2}$ levels (Fig. 1a). Note that sampling at Stations 1 and 8 reached $1250 \mathrm{~m}$ depth so SPM from $>750 \mathrm{~m}$ depth best represents the deep oxycline.

Chl $\alpha$ was highest in surface waters with maximum values of $1.8 \mu \mathrm{g} \mathrm{L}^{-1}$ at $10 \mathrm{~m}$ at Station 5 , was between 0.2 and $0.7 \mu \mathrm{g} \mathrm{L}^{-1}$ at Stations 1,2 and 8 , and decreased to values close to zero below $100 \mathrm{~m}$ at all stations (Fig. 2; see also Fiedler and Talley, 2006; Pennington et al., 2006, for additional results from previous surveys). The HPLC analysis of accessory pigments (Goericke et al., 2000; Ma et al., 2009) showed that picoplankton, primarily Prochlorococcus (indicated by divinyl chlorophyll $\alpha$ ), were an important compo- 
(a)

(b) (c)

(c) (d)

(e)

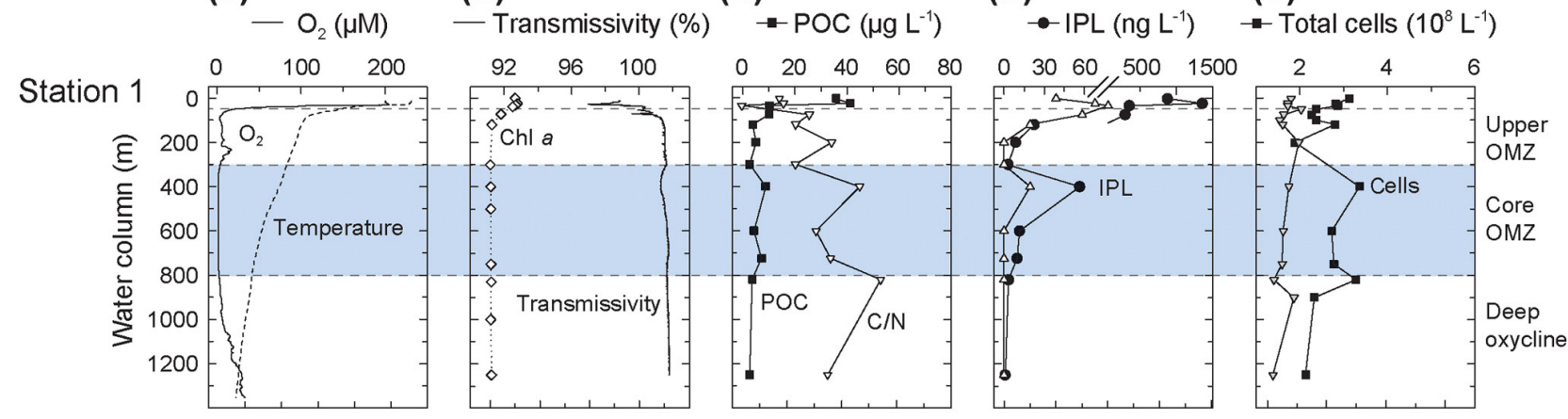

Station 2
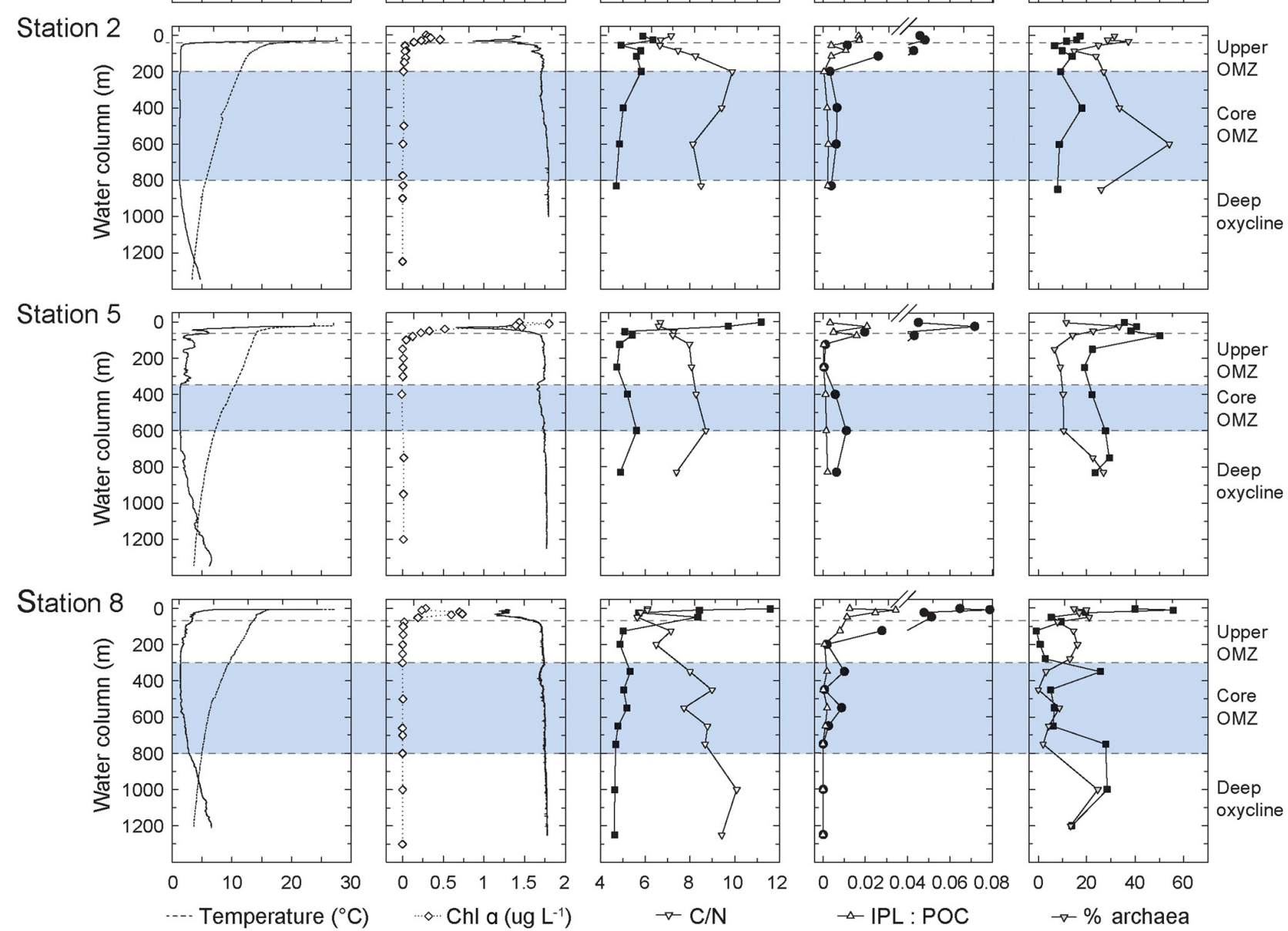

Figure 2. Depth profiles of (a) oxygen and temperature, (b) Chlorophyll $\alpha$ and transmissivity, (c) particulate organic matter (POC) and C: N, (d) ratio of intact polar lipid (IPL) to POC and IPL concentration, and (e) absolute cell abundance and relative proportions of archaeal cells (data from Podlaska et al., 2012). C : N (SPM) is the total carbon over total nitrogen of the solid phase collected by water filtration. Note that $\mathrm{C}: \mathrm{N}, \mathrm{POC}$ and IPL/POC are only analyzed for the $<53 \mu \mathrm{m}$ particle fraction. Also depicted are the different geochemical zones in the water column.

nent of the photoautotrophic community along with diatoms (fucoxanthin), especially Rhizosolenia at the deep fluorescence maximum at Stations 1 and 5, Chaetoceros at Station 8 , and prymnesiophytes (19'-hexanoyloxyfucoxanthin and 19'-butanoyloxyfucoxanthin; DiTullio and Geesey, 2002; Table S4). High phaeopigment abundances (up to $90 \%$ of
[Chl $\alpha+$ phaeopigments]) attested to algal senescence or grazing by macro- (Wishner et al., 2013; Williams et al., 2014) and microzooplankton (Olson and Daly, 2014) above and into the oxycline. Primary maxima in transmissivity corresponded with the peak Chl $\alpha$ concentrations and fluorescence maxima, but secondary transmissivity maxima be- 

(a)
(b)
(c)
(d)
(e)
$\triangle \% \mathrm{PL} \quad \triangle \% \mathrm{AL} \rightarrow \mathrm{SQ}-\mathrm{DAG}: \mathrm{PG}-\mathrm{DAG}$

$\rightarrow-\mathrm{NO}_{3}^{-}(\mu \mathrm{M}) \quad-\mathrm{PO}_{4}^{2-}(\mu \mathrm{M})$
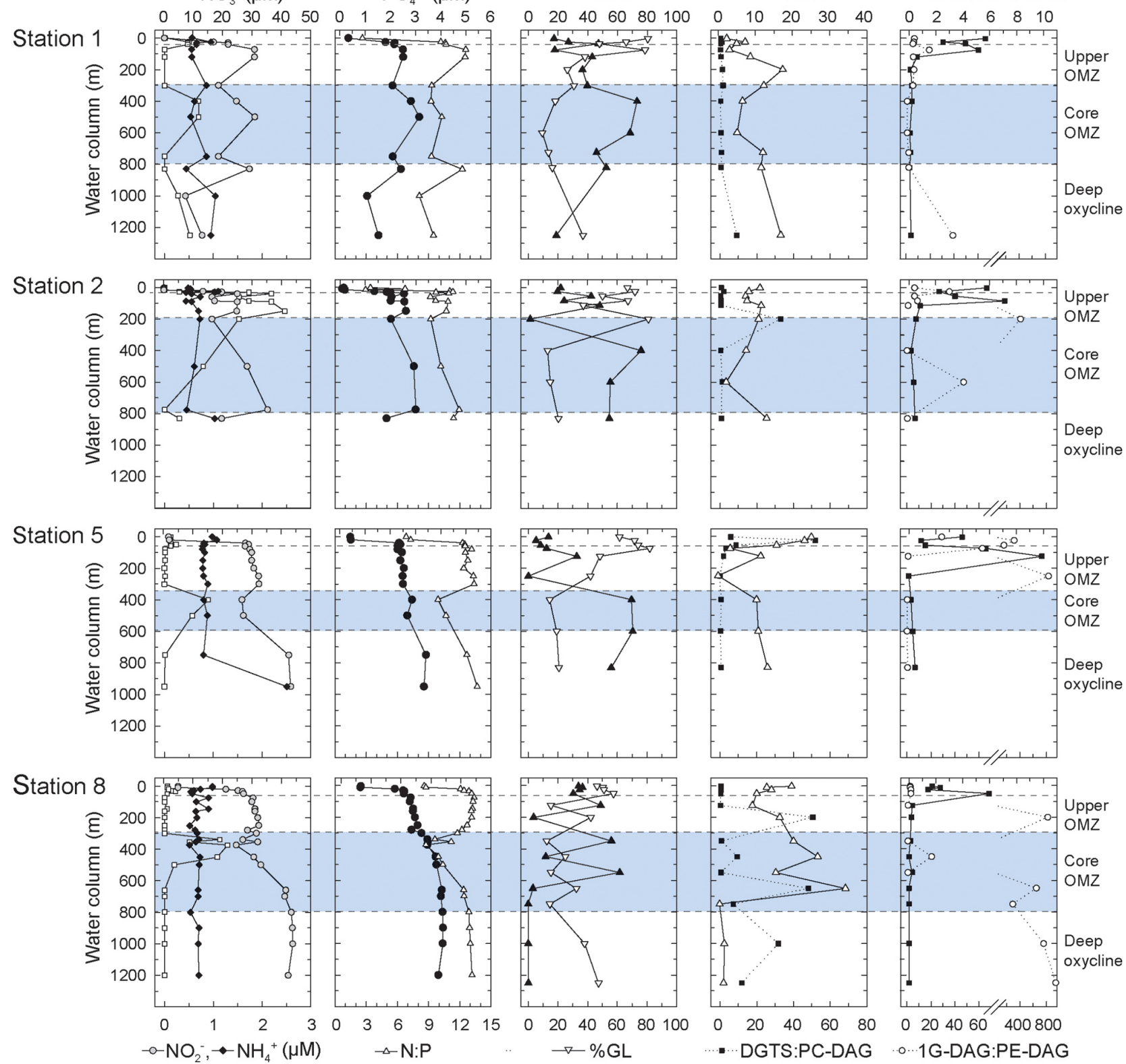

Figure 3. Depth profiles of (a) nitrate, nitrite, and ammonium; (b) phosphate and N: P; (c) total non-archaeal (non-isoprenoidal) phospholipids, glycolipids and (d) aminolipids shown as percent of total intact polar lipids and ratios of non-phospholipids to phospholipids for DGTS to PC-DAG; (e) SQ-DAG to PG-DAG; (e) and 1G-DAG to PE-DAG. Also depicted are the different geochemical zones in the water column.

tween 300 and $400 \mathrm{~m}$ at Stations 1, 5 and 8 indicated elevated particle abundances in the core of the OMZ (Fig. 2).

Nitrite $\left(\mathrm{NO}_{2}^{-}\right)$maxima in the $\mathrm{OMZ}$ at all stations coincided with nitrate $\left(\mathrm{NO}_{3}^{2-}\right)$ deficits (Fig. 3). Ammonium $\left(\mathrm{NH}_{4}^{+}\right)$concentrations changed little through the water column (Fig. 3). Phosphate ( $\mathrm{PO}_{4}^{3-}$; Fig. 3) and total dissolved nitrogen (TDN; not shown) were low (respectively, $<0.5$ and
$<3 \mu \mathrm{M}$ ) in the upper $20 \mathrm{~m}$ of the oxic zone, but they increased in the OMZ. High $\mathrm{PO}_{4}^{3-}$ (up to $3.4 \mu \mathrm{M}$ ) and high TDN (up to $44.5 \mu \mathrm{M})$ were observed in the deep OMZ at Stations 2, 5 and 8 (Fig. 3). $N: P$ ratios were lower than the Redfield ratio (16) at all sites and depths (Fig. 3); $N: P$ minima were lowest in surface waters (2.6 to 10 in the upper $20 \mathrm{~m}$ ) and were at $\sim 500 \mathrm{~m}$ within the core OMZ and the deep oxycline at Station $1(<9)$. 
POC and TN concentrations ( $<53 \mu \mathrm{m}$ material) were highest in the euphotic zone (POC: $20-100 \mu \mathrm{g} \mathrm{L}^{-1}$; TN: 4$15 \mu \mathrm{g} \mathrm{L}^{-1}$ ), rapidly dropping to 5 and $1 \mu \mathrm{g} \mathrm{L}^{-1}$ below the upper OMZ, respectively (Figs. 2 and S2). Secondary maxima for POC $\left(\sim 10 \mu \mathrm{g} \mathrm{L}^{-1}\right)$ and $\mathrm{TN}\left(\sim 2 \mu \mathrm{g} \mathrm{L}^{-1}\right)$ within the core of the OMZ might reflect elevated microbial biomass there. Concentrations dropped in the deep oxycline to $\leq 3$ and $\leq 0.5 \mu \mathrm{g} \mathrm{L}-1$ for POC and TN, respectively.

Absolute IPL concentrations were determined by ion trap LCMS, varied between 250 and $1500 \mathrm{ng} \mathrm{L}^{-1}$ in the oxic zone, and abruptly decreased by more than 10 fold (to $<20 \mathrm{ng} \mathrm{L}^{-1}$ ) in the upper OMZ (Fig. 2). Secondary maxima in IPL concentrations (15-40 $\mathrm{ng} \mathrm{L}^{-1}$ ) within the OMZ at all stations roughly coincided with elevated numbers of prokaryotes (Fig. 2). IPL: POC ratios decreased with increasing depth (Fig. 2), tracking trends of POC, TN and IPL concentrations.

\subsection{Changes in IPL composition with water column depth in the ETNP}

In total, 24 IPL classes were identified in the ETNP (Figs. 4 and S3). IPL classes (11 major and 13 minor) were detected in the QTOF analyses, which were classified according to their relative abundance; if an individual IPL comprised more than $10 \%$ of total IPLs at any depth of the four stations, it was classified as a major IPL, and compounds $<10 \%$ were minor IPLs. Based on their head-group composition, IPLs were grouped into glycolipids, phospholipids or aminolipids. Figure 3 shows changes in the relative abundances (as percentages of total IPLs, excluding isoprenoidal archaeal IPLs) of glycolipids, phospholipids and aminolipids as well as several substitute lipid ratios, reflecting the preferential biosynthesis of non-phosphorus lipids to replace phospholipids under phosphate-limiting growth (cf. Van Mooy et al., 2006; Popendorf et al., 2011b; Carini et al., 2015; Bosak et al., 2016). Relative abundances of non-isoprenoidal phospholipids were highest in the core OMZ between 400 and $600 \mathrm{~m}$ at all sites, where they comprise up to $45 \%-76 \%$ at Stations 1,2 and 5 and between $12 \%$ and $61 \%$ at Station 8. Phospholipid abundances were lower within the upper OMZ and oxic zone at all stations (between $4 \%$ and $55 \%$ ) and in the deep oxycline at Station $8(<1 \%)$. Aminolipid content was highest in SPM from the upper $55 \mathrm{~m}$ at Stations 5 and $8(10 \%$ to $25 \%)$, the core OMZ at Station $8(15 \%$ to $34 \%)$, and the deep oxycline at Station $1(17 \%)$. Lower aminolipid contents ( $2 \%$ to $11 \%$ ) were observed in the oxic zone and the core OMZ at Stations 1 and 2, the upper OMZ at Station $5(0 \%$ to $11 \%)$, and the deep oxycline at Station $8(<2 \%)$. Glycolipid abundance was $>9 \%$ at all depths, with the highest abundance (average $54 \%$, maximum $82 \%$ ) within the upper OMZ and oxic zone at all stations and the deep oxycline at Station 8 . Values down to $9 \%$ were observed within the core OMZ.

\subsubsection{Major lipids}

The 11 major IPL classes included three IP-GDTs of archaeal origin (1G-GDGT, 2G-GDGT and HPH-GDGT) and eight IPLs assigned to either a bacterial or eukaryotic origin: three glycolipids (1G-DAG, 2G-DAG and SQ-DAG), four phospholipids (PG-DAG, PE-DAG, PC-DAG and PE + PC-AEG) and one aminolipid (DGTS). All major lipid classes were found at almost all depths at all four stations but with varying relative abundances (as \% of total IPL; Fig. 4, Table S1).

Archaeal IP-GDGTs. Relative abundances of archaeal IPL (IP-GDGTs) generally increased with depth, from undetectable in surface waters to $>50 \%$ of total IPLs at Station 8 (bottom of core OMZ and deep oxycline). Archaeal IP-GDGT abundances at Stations 1 and 2 peaked at $30 \%$ (bottom of upper OMZ, core OMZ and deep oxycline) but were generally $<10 \%$ at Station 5 (Fig. 4). At Stations 1 and 2,1G-GDGT and 2G-GDGT were most abundant with variable amounts of HPH-GDGTs, whereas 1G-GDGT and HPH-GDGT dominated archaeal IPLs at Stations 5 and 8 at most depths. Distributions of glycosidic IPL-GDGTs obtained in the present investigation corroborate the absolute values reported by (Xie et al., 2014) for Stations 1 and 8; 1GGDGT was more abundant than 2G-GDGT at Station 8 when compared to Station 1. The core GDGTs of 1G-GDGTs and HPH-GDGTs are dominated by GDGT-0 and crenarchaeol (Fig. S4), whereas 2G-GDGTs are dominated by GDGT-2 and a small amount of crenarchaeol (Zhu et al., 2016)

Diacylglycerol lipids. The oxic zone and the upper OMZ were dominated ( $\sim 50 \%-80 \%$ of IPL) at all sites by the diacylglycerol glycolipids: 1G-DAG, 2G-DAG and SQ-DAG (Fig. 4). In the core $\mathrm{OMZ}$ and deep oxycline, relative amounts of $2 \mathrm{G}-\mathrm{DAG}$ and SQ-DAG decreased to $4 \%$ and $12 \%$, respectively. $1 \mathrm{G}-\mathrm{DAG}$ abundances were lowest in the core OMZ at all stations, but they were up to $47 \%$ of total IPL in the deep oxycline. Diacylglycerol phospholipids (PE, PG- and PC-DAG) were the second most abundant IPLs. Abundances of PE- and PG-DAG were highest within the upper and core OMZ, constituting $>50 \%$ in the core OMZ at Station $1,>30 \%$ at Stations 2 and 5, and $16 \%$ at Station 8. PC-DAG, with an average abundance of $5 \%$ at Stations 1 , 2 and 8 and an average abundance of $3 \%$ at Station 5, did not exhibit depth-related trends. The third most abundant diacylglycerol class was the betaine lipid DGTS, which was present throughout the water column at average abundances of $7 \%$ at Stations 1, 2 and 8 and $5 \%$ at Station 5.

Major diacylglycerol lipids showed changes in the average number of carbon atoms and double bond equivalents (DBE) with depth (Fig. 5, Table S5). The glycolipids and PC-DAG decreased in average carbon number by up to three carbons and decreased in DBE by up to 2 at the top of the upper OMZ and within the core OMZ, compared to the oxic zone and the deep oxycline. Average carbon numbers for PE- and PG-DAG and DGTS showed an inverse trend, both generally increasing by up to two carbons between the upper OMZ and 
Major compounds

\begin{tabular}{|lll|}
\hline \multicolumn{2}{|l|}{ Bacteria and eukarya } \\
Glycolipids & Phospholipids & Aminolipids \\
WX 1G-DAG & PG-DAG & DI DGTS \\
2G-DAG & PE-DAG & \\
SQ-DAG & PE+PC-AEG \\
& PC-DAG & \\
Archaea & & $\square$ Minor \\
glycolipids & Phospholipids & compounds \\
WX 1G-GDGT & HPH-GDGT \\
XX 2G-GDGT & \\
\hline
\end{tabular}

Relative abundance (\%)

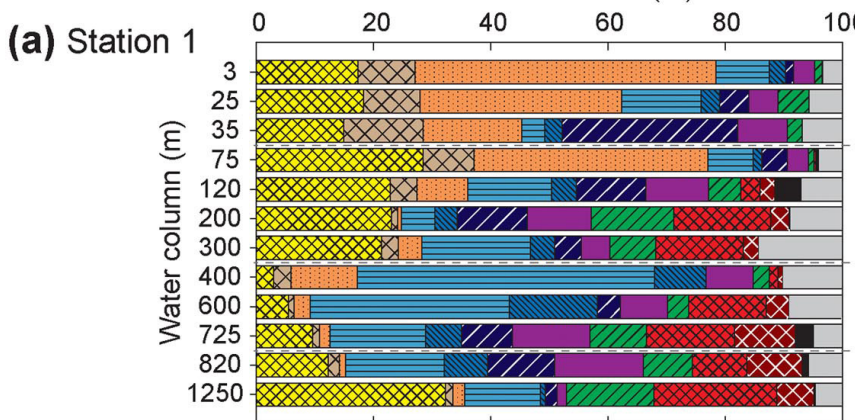

(b) Station 2

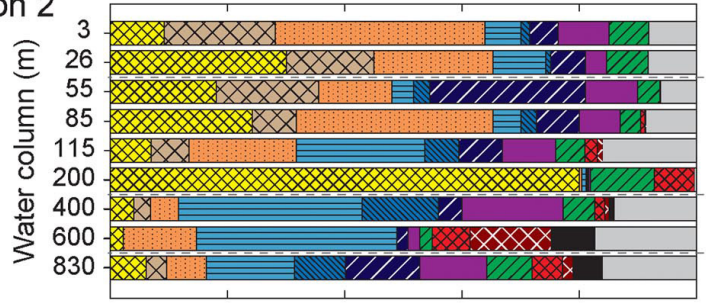

(c) Station 5

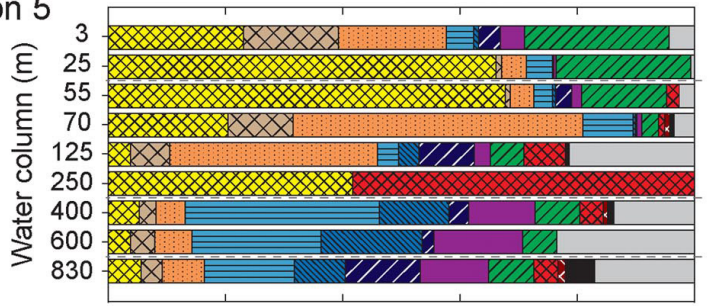

(d) Station 8

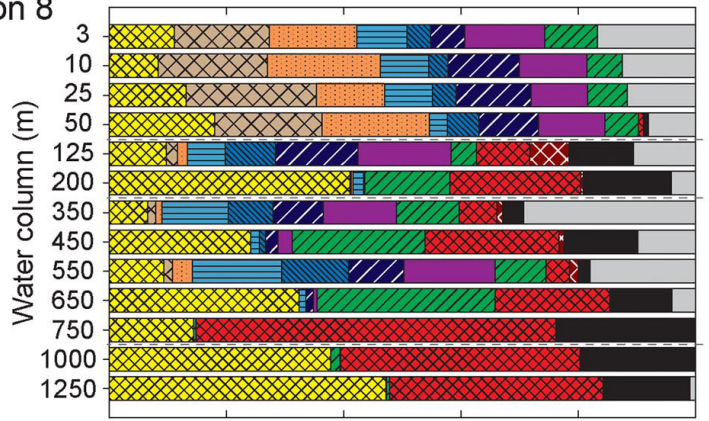

\section{Minor compounds}

\begin{tabular}{|lll|}
\hline \multicolumn{2}{l|}{ Bacteria and eukarya } & \\
Glycolipids & Phospholipids & Aminolipids \\
1G-OH-DAG & DPG & OH-DGTS \\
3G-DAG & DII PME-DAG & $\square$ AL-1 \\
SQ-AEG & III PDME-DAG & $\square$ AL-II \\
$\square$ 1G-CER & PI-DAG & $\square$ OL \\
1G-OH-CER & & \\
\hline
\end{tabular}

Relative abundance (\%)
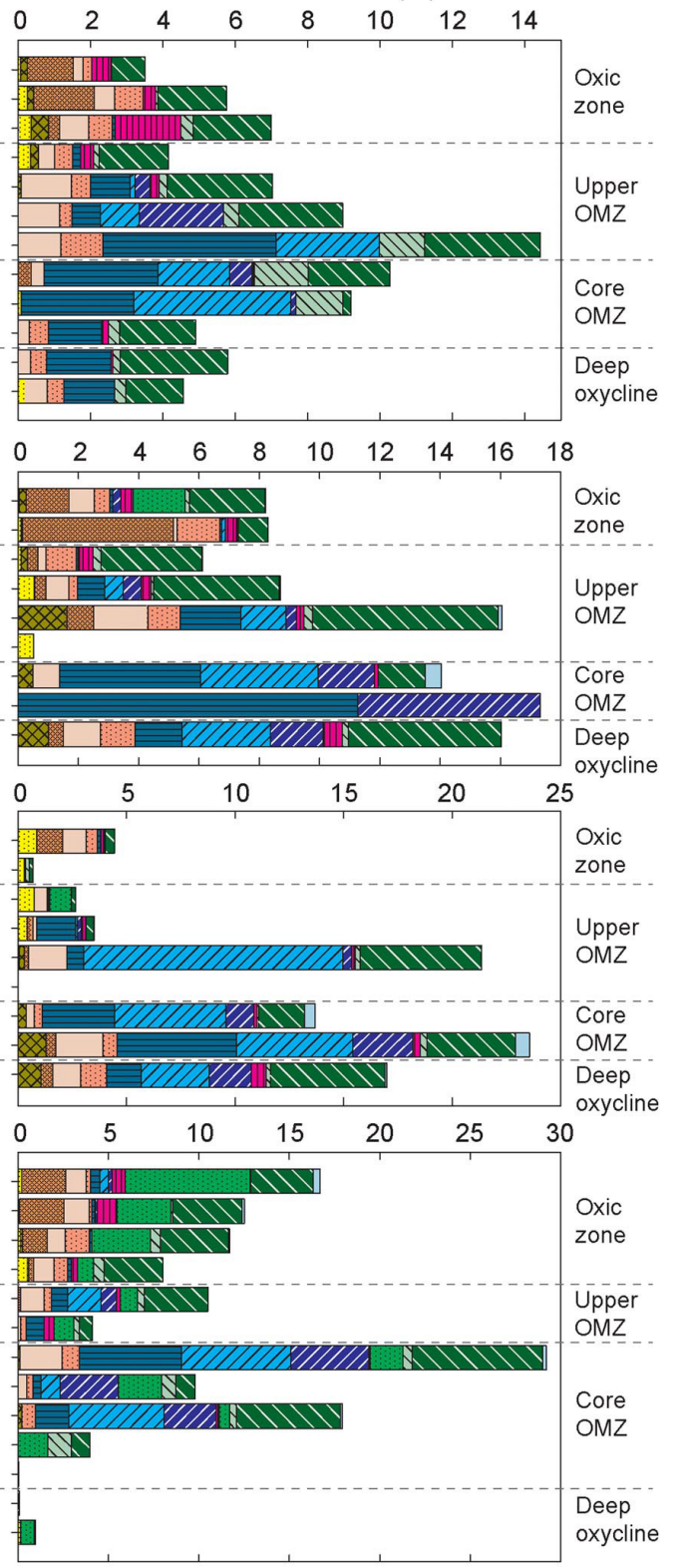

Figure 4. Relative abundance of (a) major and (b) minor IPLs at sampled depths of Stations 1, 2, 5 and 8 in the ETNP. Major IPLs are defined as those comprising more than $10 \%$ of total IPLs (minor compounds comprised less than $10 \%$ ) at more than one depth horizon at the four stations. Also depicted are the different geochemical zones in the water column. 


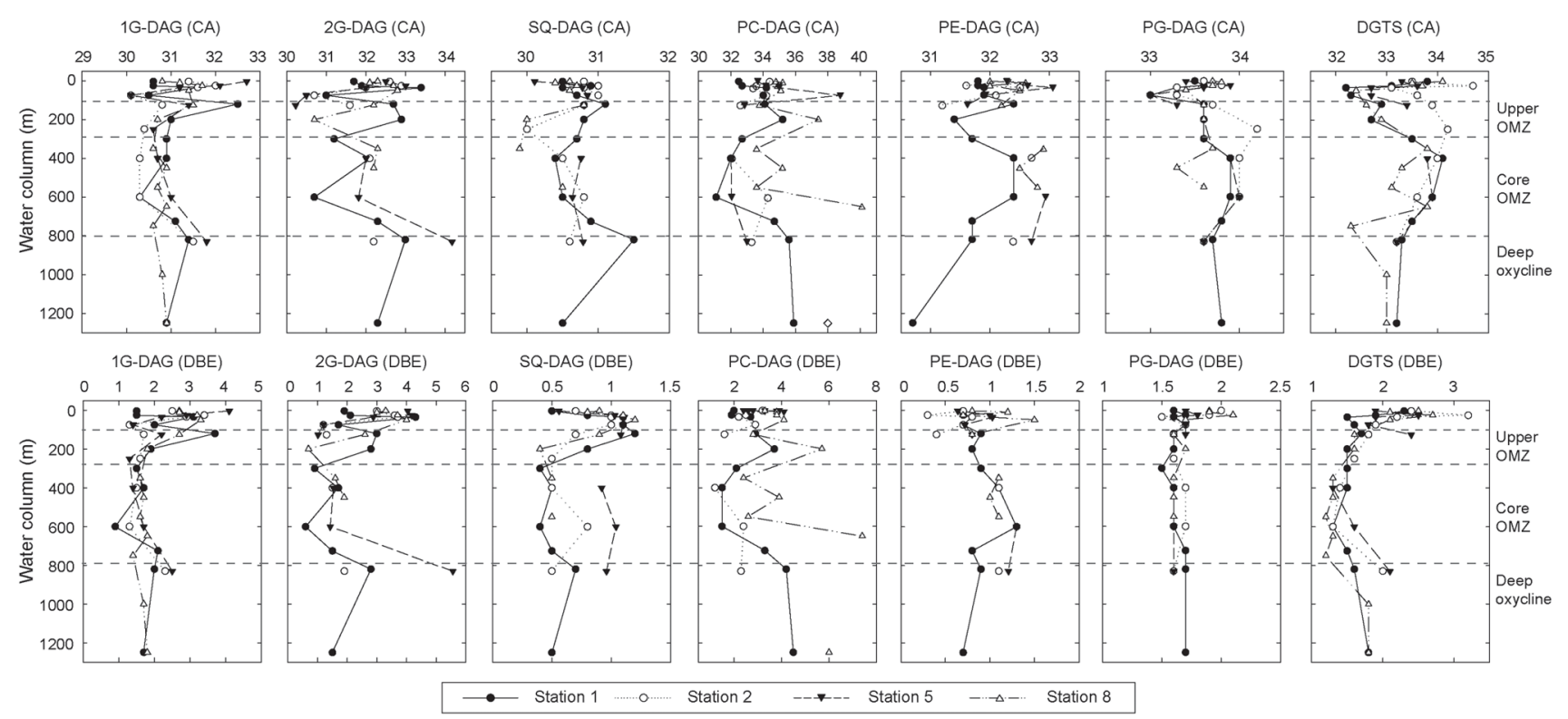

Figure 5. Changes in average carbon atoms (CA) and number of double bond equivalents (DBE) of the alkyl side chains of major IPLs detected at Stations 1, 2, 5 and 8 in the ETNP.

the core OMZ. Changes in DBE were not as pronounced for PG-DAG and DGTS; on average, changes were one to two DBE greater in surface waters than in deeper waters, while the number of DBE increased on average with depth for PEDAG.

Acyl-ether glycerol lipids. Mixed ether-ester glycerol core structures with either PE or PC head groups were observed at all stations and all depths (generally $4 \%-12 \%$ ) except for the deep oxycline at Station 8.

\subsubsection{Minor lipids}

Thirteen minor IPL classes were identified, five of which were glycolipids, four phospholipids and four aminolipids. All minor lipid classes were detected at each site, except for OH-DGTS, which was absent at Station 1. Some minor lipids were found at all depths, whereas others were restricted to specific depth zones as defined by oxygen content (Fig. 4).

Diacylglycerol lipids. Two minor diacylglycerol glycolipids, 1G-OH-DAG and 3G-DAG, were most abundant within the oxic zone and the upper OMZ, comprising between $2 \%$ to $15 \%$ of minor lipids on average $(0.1 \%$ to $0.6 \%$ of total IPLs), but they were only found sporadically within the core OMZ and deep oxycline. 1G-OH-DAG showed the highest relative abundances at Station 5, constituting up to $40 \%$ of minor lipids. Four additional phospholipids with diacylglycerol core structures with the following head groups were identified: diphosphatidylglycerol (DPG), phosphatidyl- $N$-methylethanolamine (PME), phosphatidyl$N, N$-dimethylethanolamine (PDME) and phosphatidylinositol (PI). DPG, PME-DAG and PDME-DAG had highest rel- ative abundances (respectively $65 \%, 56 \%$ and $35 \%$ of minor IPLs) within the upper and core OMZ, but there were lower abundances within the oxic zone at all stations and in the deep oxycline at Stations 1, 2 and 5. PI-DAG was most abundant in the oxic zone and the upper OMZ (up to $25 \%$ of minor IPL), but it was also present in the core OMZ and the deep oxycline, except for at Station 8. Three types of aminolipids were observed as minor lipids. OH-DGTS with up to three hydroxyl groups attached to the fatty acyl side chains (Fig. S5) was observed at most depths at Station 8 , with an average relative abundance of $23 \%$ among the minor lipids; it was also occasionally detected at Stations 2 and 5 within the oxic zone and upper OMZ. Two additional aminolipids had an undefined head group that exhibited fragmentation patterns characteristic of betaine lipids, but they did not have established betaine head-group fragments (Fig. S6b, c). The tentatively assigned sum formula for the head group of the first unknown aminolipid (AL-I) at ca. 6.7 min liquid-chromatography (LC) retention time was $\mathrm{C}_{8} \mathrm{H}_{17} \mathrm{NO}_{3}$, and for the second unknown aminolipid (AL-II) at 10.5 min was $\mathrm{C}_{7} \mathrm{H}_{15} \mathrm{NO}_{3}$. The head-group sum formula for AL-II matches that of DGCC, but the diagnostic head-group fragment of $\mathrm{m} / \mathrm{z} 252$ was not detected; furthermore, AL-II did not elute at the expected earlier retention time for DGCC. AL-I and AL-II were detected at most depths at all four stations, with average abundances of $1 \%$ to $6 \%$ of the minor lipids for AL-I and comparably higher relative abundances ranging from $16 \%$ to $36 \%$ for AL-II.

Acyl-ether glycerol lipid. One minor compound that eluted slightly earlier than SQ-DAG had a fragmentation pattern similar to SQ-DAG but with exact masses of the parent ion 


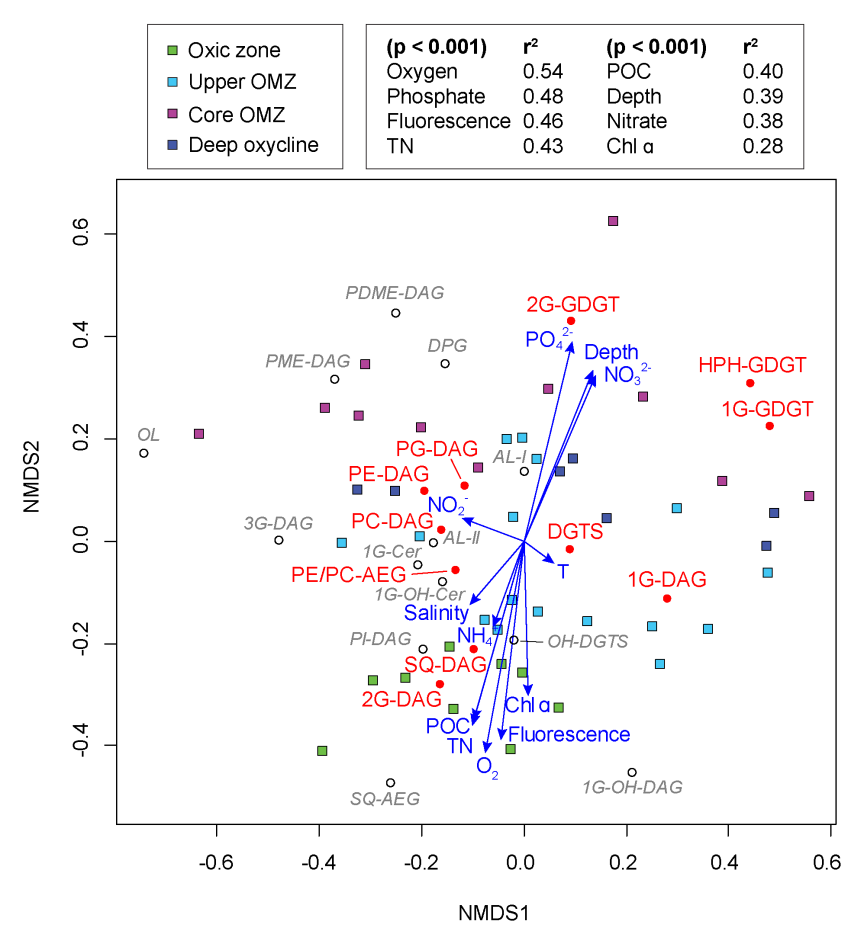

Figure 6. Nonmetric multidimensional scaling (NMDS) ordination plot assessing the relationship between IPL biomarkers, sampling depths and geochemical parameters in the ETNP (stress of 0.125). Squares represent the water depth of each sample and are colorcoded according to the defined geochemical zonation. Filled circles stand for the lipid distribution of major IPLs and open circles for minor IPLs on the ordination. Vector lines of geochemical parameters are weighted by their $p$ values with each NMDS axis.

and MS-MS fragments in both positive and negative ion mode that suggested a mixed acyl-ether glycerol core lipid structure (Fig. S6d, e). Tentatively assigned as SQ-AEG, this IPL was observed at most depths at all four stations, with the highest relative abundances of $5 \%$ to $60 \%$ of minor IPLs within the oxic zone.

Sphingolipids. Two types of sphingolipids were identified, monoglycosyl ceramide (1G-CER) and hydroxylated monoglycosyl ceramide (1G-OH-CER), with up to two hydroxyl groups attached to the hydrophobic side chains (Fig. 5e). Both were observed at all depths at Stations 1,2, and 5 at average relative abundances between $3 \%$ and $8 \%$ of minor IPLs, but neither was detected in the deeper part of the core $\mathrm{OMZ}$ or deep oxycline at Station 8.

Ornithine lipids. Trace amounts $(<4 \%)$ of ornithine lipids were detected in the core OMZ of Stations 2 and 5.

\subsubsection{Statistical relationships between environmental parameters and lipid distribution}

Spearman's rank order correlation was used to evaluate relationships between relative lipid abundance of lipid classes and environmental parameters (Table 1). The glycolipids 2G- and SQ-DAG showed highly significant $(p<0.001)$ and positive correlations with depth, fluorescence, POC, TN, temperature and $\mathrm{Chl} \alpha$; significant positive correlations were also observed with oxygen. Both also showed highly significant but negative correlations with phosphate and nitrate, and these overall trends were mirrored in the SQ-DAG: PGDAG ratio. Total glycolipids (GL) and 1G-DAG only showed correlations with a few environmental parameters, and total GL only significantly positively correlated with oxygen. Most aminolipids and phospholipids did not show significant correlations with environmental parameters, and any other correlations were neither strongly positive nor negative. The relative abundances of total ratios of aminolipids and aminolipid (AL) to phospholipid (PL) correlated positively with ammonium. AL : PL also correlated positively with oxygen. Relative abundance of total phospholipids and most individual phospholipids (PG-, PE-, PME- and PDME-DAG) correlated negatively with oxygen. The only phospholipid that significantly correlated with phosphate was PDME; however, the positive correlation is not strong $\left(r^{2}<0.4\right)$.

NMDS analysis revealed that all samples from the oxic zone had a negative loading on the NMDS- 2 axis along with environmental variables such as oxygen, fluorescence, $\mathrm{TN}$, POC and Chl $\alpha$. The IPLs with a strong negative loading on the NMDS-2 axis $(<-0.2)$ were $1 \mathrm{G}-\mathrm{OH}-\mathrm{DAG}$, SQ-AEG, 2G-DAG, SQ-DAG, PI-DAG and OH-DGTS. Most samples from the core OMZ and deep oxycline had a positive loading on the NMDS-2 axis, together with depth, phosphate and nitrate. IPLs that showed a strong positive loading on the NMDS-2 axis (>0.2) were PDME-DAG, 2G-GDGT, DPG, PME-DAG and HPH-GDGT. Almost all environmental variables had low $p$ values $(<0.001)$, indicating highly significant fitted vectors with the exception of temperature, salinity, ammonium and nitrate. The highest goodness-of-fit statistic was observed with oxygen $\left(r^{2}=0.54\right)$, followed by phosphate $\left(r^{2}=0.48\right)$ and then fluorescence $\left(r^{2}=0.46\right)$.

\section{Discussion}

The moderate primary productivity in surface waters of the ETNP, intense microbial degradation of particulate organic matter exported to the thermocline and restricted midwater oxygen replenishment produce the strong, shallow $(\sim 20 \mathrm{~m}$ deep) oxycline and a $\sim 500 \mathrm{~m}$ thick OMZ with dissolved oxygen concentrations of $<2 \mu \mathrm{M}$, not unlike other oceanic OMZs (e.g., Ulloa et al., 2012). The ETNP is dominated by picoplankton, and micro-grazers were reported as consuming most phytoplankton production (Landry et al., 2011; Olsen and Daly, 2014). Peak macrozooplankton biomass was located at the thermocline, near the upper boundary of the OMZ, but a secondary biomass peak of a different zooplankton assemblage was present at the deep oxycline once $\mathrm{O}_{2}$ concentrations rose to $\sim 2 \mu \mathrm{M}$ (Wishner et al., 2013). Shallow-water, plankton-derived particulate organic carbon 
Table 1. Spearman's rank order correlation coefficients $(r)$ for data combined from all four stations. Only significant correlations where $p<0.05$ (highly significant $p<0.001$ in bold) are presented.

\begin{tabular}{|c|c|c|c|c|c|c|c|c|c|c|c|c|c|c|c|c|}
\hline & \multicolumn{6}{|c|}{ Glycolipids } & \multicolumn{4}{|c|}{ Aminolipids } & \multicolumn{6}{|c|}{ Phospholipids } \\
\hline & $\% \mathrm{GL}$ & $\% 1 \mathrm{G}$ & $\% 2 \mathrm{G}$ & $\%$ SQ & GL:PL & SQ:PG & $\% \mathrm{AL}$ & $\%$ DGTS & $\mathrm{AL}: \mathrm{PL}$ & DGTS : PC & $\% \mathrm{PL}$ & $\% \mathrm{PC}$ & $\% \mathrm{PG}$ & $\% \mathrm{PE}$ & $\%$ PME & $\%$ PDME \\
\hline Depth & -0.32 & & -0.7 & -0.67 & -0.41 & -0.76 & & & & & & & & & & \\
\hline Fluorescence & & & 0.63 & 0.67 & & 0.65 & & & & & & & & & & \\
\hline POC & & & 0.61 & 0.6 & & 0.6 & & & & & & & & & & \\
\hline $\mathrm{TN}$ & & & 0.66 & 0.62 & & 0.63 & & & & & & & & & & \\
\hline Oxygen & 0.57 & 0.3 & 0.48 & 0.35 & 0.55 & 0.58 & & & 0.36 & & -0.49 & & -0.38 & -0.33 & -0.46 & -0.52 \\
\hline Temperature & 0.3 & & 0.52 & 0.63 & 0.39 & 0.69 & & & & & & & & & & \\
\hline $\operatorname{Chl} \alpha$ & 0.35 & & 0.72 & 0.71 & 0.42 & 0.78 & & & & & & & & & & -0.33 \\
\hline Phosphate & & & -0.62 & -0.53 & -0.4 & -0.56 & & & & & & & & & & 0.36 \\
\hline Nitrate & & & -0.53 & -0.49 & & -0.38 & & & & & & & & & & \\
\hline Nitrite & & -0.33 & & & & & & & & & & & & & 0.3 & \\
\hline Ammonium & & & & & & & 0.41 & 0.42 & 0.35 & 0.4 & & & & & & \\
\hline $\mathrm{N}: \mathrm{P}$ & & & -0.3 & -0.32 & & & & & & & & & -0.36 & & & \\
\hline
\end{tabular}

Abbreviations: GL - glycolipids, $1 \mathrm{G}$ - monoglycosyl, 2G - diglycosyl, SQ - sulfoquinovosyl, PL - phospholipids, AL - aminolipids, DGTS - diacylglyceryl trimethyl homoserine, PC - phosphatidyl choline, PG - phosphatidyl glycerol, PE - phosphatidyl ethanolamine, PME - phosphatidyl methyl-ethanolamine and PDME - phosphatidyl dimethyl-ethanolamine.

is the primary food source for zooplankton in the mixed layer, upper oxycline and core OMZ, whereas deep POC, some of which might have been produced by microbes in the OMZ, is important for deep oxycline zooplankton (Williams et al., 2014). Microbial community structure and activities are typical of other OMZs (Taylor et al., 2001; Lin et al., 2006; Woebken et al., 2007; Wakeham et al., 2007, 2012). Cell numbers of total prokaryotes were highest in the euphotic layer and decreased with depth at the thermocline but rose again within the core OMZ (Podlaska et al., 2012). Elevated rates of chemoautotrophy, measured by dark dissolved inorganic carbon (DIC) assimilation, were observed at several depths in the OMZ and in the lower oxycline. The transfer of chemoautotrophically fixed carbon into zooplankton food webs is also evident (Williams et al., 2014). Bacteria dominate the prokaryotic community at all stations. Nitrifying bacteria constituted 3\%-7\% of total DAPIpositive prokaryotes in surface waters; sulfate-reducing bacteria (17\% and $34 \%$ of total prokaryotes), planctomycetes (up to $24 \%$ of total prokaryotes) and anammox bacteria ( $<1 \%$ of prokaryotes) in the upper OMZ and deep oxycline might be associated with anoxic micro-zones within particle aggregates even at low dissolved oxygen concentrations (Woebken et al., 2007; Carolan et al., 2015). Archaeal cell abundances peaked at the start of the upper OMZ at all stations (up to $37 \%$ of total prokaryotes at Station 2), within the core OMZ at Station 2 (up to $54 \%$ of total detected cells) and within the deep oxycline at Stations 5 and 8 (around 25\%; Fig. 2e). crenarchaeota/thaumarchaeota represented $\sim 20 \%$ of prokaryotes throughout the water column, generally being highest in the lower OMZ and deep oxycline, and at Stations 2 and 5, they were just above the secondary $\mathrm{Chl} a$ maxima at $\sim 75 \mathrm{~m}$. Euryarchaeota were $16 \%-20 \%$ of total prokaryotes, especially in waters above the OMZ.

Total IPL concentrations that were over 50 times higher in the surface waters than at deeper depths coinciding with high $\mathrm{Chl} \alpha$ concentrations, reflecting the importance of pho- totrophic sources to the IPL pool above the thermocline. Below the thermocline, IPL concentrations generally track trends in microbial cell abundances, and elevated IPL concentrations in the upper and core OMZ coincide with elevated nitrite concentrations. The rapid decrease in IPL concentrations below $\sim 100 \mathrm{~m}$ probably results from a combination of a dearth of potential source organisms and the decomposition of sinking detrital lipids (Harvey et al., 1986; Matos and Pham-Thi, 2009). IPL concentration decreases below the euphotic zone are well established (Van Mooy et al., 2006; Schubotz et al., 2009; Van Mooy and Fredricks, 2010; Popendorf et al., 2011b; Wakeham et al., 2012). We believe that the diverse molecular compositions and shifts in the relative abundances of IPLs with changing geochemistry reflect a complex biological community structure and their ecophysiological adaptation throughout the water column.

\subsection{Provenance of IPLs in the ETNP}

Variations in IPL distributions and head-group and core lipid compositions reflect the biogeochemical stratification of the water column. Below we discuss potential sources of and possible physiological roles for IPLs in the different zones.

\subsubsection{Oxic zone}

The glycosyl diacyl glycerides that dominate the IPL composition in oxic surface waters, 1G-DAG, 2G-DAG and SQDAG, are major constituents of photosynthetic thylakoid and chloroplast membranes (Wada and Murata, 1998; Siegenthaler, 1998) and are therefore generally assigned to photosynthetic algae or cyanobacteria (Van Mooy et al., 2006; Popendorf et al., 2011b). These are also the likely predominant sources in our study; however, notably 1G-DAG may also be synthesized by heterotrophic bacteria (Popendorf et al., 2011a; Carini et al., 2015; Sebastian et al., 2016). In the oxic zone, 1G- and 2G-DAG are predominantly comprised of $\mathrm{C}_{16}$ and $\mathrm{C}_{18}$ fatty acids with zero to 5 double-bond- 
equivalent polyunsaturated acid (PUFA) combinations, such as $\mathrm{C}_{16: 4} / \mathrm{C}_{18: 3}, \mathrm{C}_{16: 4} / \mathrm{C}_{18: 4}, \mathrm{C}_{18: 3} / \mathrm{C}_{16: 2}, \mathrm{C}_{18: 4} / \mathrm{C}_{14: 0}$ and $\mathrm{C}_{18: 5} / \mathrm{C}_{14: 0}$ (Table S5, Fig. 5). These are characteristic of eukaryotic algae (Brett and Müller-Navarra, 1997; Okuyama et al., 1993), such as diatoms and prymnesiophytes, which are the major eukaryotic phytoplankton in the ETNP. The SQ-DAG biosynthesized by cyanobacteria does not contain PUFA, but instead predominantly contains combinations of $\mathrm{C}_{14: 0}, \mathrm{C}_{16: 0}$ and $\mathrm{C}_{16: 1}$ fatty acids (e.g., Siegenthaler, 1998), yielding shorter chain lengths and a lower average number of double bonds ( 0.5 to 1$)$ than the other glycolipids as observed at the ETNP (Fig. 5). Betaine lipids (DGTS) in the surface waters of the ETNP are comprised of $\mathrm{C}_{14}, \mathrm{C}_{16}, \mathrm{C}_{18}$ and $\mathrm{C}_{20}$, with multiple unsaturations or rings (on average 1.5 to 3 double bond equivalents), and they are also likely derived from phytoplankton (Dembitsky, 1996; Popendorf et al., 2011a).

PC-DAG with fatty acyl combinations of $\mathrm{C}_{22: 6}$ and $\mathrm{C}_{20: 5}$ long-chain PUFA and $\mathrm{C}_{16: 0}$ fatty acids (Table S5) in surface waters also points to primarily eukaryotic algal sources. PG-DAG is the only phospholipid in cyanobacteria and thylakoid membranes of eukaryotic phototrophs (Wada and Murata, 1998). Heterotrophic bacteria are an additional source for PG-DAG, since it can be a major phospholipid in bacterial membranes (Goldfine, 1984). PE-DAG is a minor phospholipid in eukaryotic algae (e.g., Dembitsky et al., 1996) but is common in membranes of bacteria (Oliver and Colwell, 1973; Goldfine, 1984) and is biosynthesized by heterotrophic marine bacteria (Popendorf et al., 2011a). Lower average numbers of double bond equivalents in PG- and PEDAG $(<2)$ in the upper water column of the ETNP are consistent with a bacterial origin (Fig. 5).

Oxic ETNP waters contain PE- and PC-based phospholipids with mixed acyl and ether core lipids (AEG), which are often referred to as 1-O-monoalkyl glycerol ethers (MAGE) if detected as core lipids. PE-AEG have been described in some sulfate-reducing bacteria (Rütters et al., 2001), which in the oxic zone or OMZ of the ETNP would require anoxic micro-zones in fecal pellets or aggregates (e.g., Bianchi et al., 1992; Shanks and Reeder, 1993). In the ETNP, MAGEbased phospholipids were $1 \%$ to $30 \%$ of total IPLs. MAGE, detected as core lipids in surface waters of the Southern Ocean and eastern South Atlantic, are thought to be breakdown products of IP-AEGs of an aerobic bacterial origin (Hernandez-Sanchez et al., 2014), but culturing experiments have yet to confirm this conclusion. Similarly, aerobic bacteria (possibly cyanobacteria) are likely sources for SQ-AEG, since sulfoquinovosyl is a diagnostic head group found in cyanobacteria, although, again, these lipids have not been reported in cultured cyanobacteria. Other minor phospholipids in the euphotic zone include PI-DAG and DPG. They are minor components in several marine algae (Dembitsky, 1996) and bacteria (Morita et al., 2010; Diervo et al., 1975; Mileykovskaya and Dowhan, 2009). Bacteria may also be the source of the low detected levels of $N$-methylated phos- pholipids PME-DAG and PDME-DAG (Goldfine and Ellis, 1964). The 3G-DAG comprised of $\mathrm{C}_{14}, \mathrm{C}_{16}$ and $\mathrm{C}_{18}$ fatty acids with up to six double bond equivalents is another minor IPL detected in the euphotic zone at all stations except for Station 5. It has been found in some plants (Hölzl and Dörmann, 2007) and some anaerobic gram-positive bacteria (Exterkate and Veerkamp, 1969), which could both be probable sources in the oxic euphotic zone of the ETNP.

The sphingolipid, 1G-CER, consists of a sphingosine backbone linked to a fatty acid via an amide bond and was a minor component in the oxic zone ( $<5 \%$ of IPL) at all stations (Fig. 4). Glycosidic ceramides occur in eukaryotic algae such as the coccolithophore Emiliania huxleyi (Vardi et al., 2009). We also detected 1G-OH-CER with up to two hydroxylations in the core lipid structure (Fig. S5). Multiplehydroxylated sphingoid bases are potential markers of viral infection and cell death in at least some marine phytoplankton, notably E. huxleyi (Vardi et al., 2009). We did not, however, find mass spectral evidence for the presence of viral polyhydroxylated 1G-CER, as described by Vardi et al. (2009), and therefore rather suggest that eukaryotic algal cells are potential sources for the 1G-CER (Lynch and Dunn et al., 2004) in surface waters of the ETNP. We also detected hydroxylated glycolipids (1G-OH-DAG) and aminolipids (OH-DGTS) with up to two hydroxyl groups or one hydroxyl group combined with an epoxy or keto function attached to the acyl groups (Fig. S5). The addition of hydroxyl groups or the general oxidation of fatty acids in plants, algae and yeast is a defense mechanism and response to oxidative stress (Kato et al., 1984; Andreou et al., 2009). Hydroxy fatty acids, for example, are intermediates in the oxidative degradation of fatty acids (Lehninger, 1970), and since they are constituents of structural biopolymers of many microorganisms (Ratledge and Wilkinson, 1988), they are present in marine particulate matter (e.g., Wakeham, 1999), likely derived from membrane constituents of Gram-negative bacteria, the most abundant bacteria in seawater (Rappé et al., 2000).

\subsubsection{Upper OMZ}

Glycolipid abundance varied from $15 \%$ to $80 \%$ of total IPL within the upper OMZ below the thermocline/oxycline. SQDAG and 2G-DAG exhibited strong decreases in relative and absolute abundance below $125 \mathrm{~m}$ at all stations, consistent with the decrease in their phototrophic biomass. The number of carbon atoms in the core lipid chains and the number of double bond equivalents of glycolipids showed considerable variations within the upper OMZ (Fig. 5), indicating a different assemblage of source organisms compared to the oxic zone. Likewise, decreasing carbon numbers and double bond equivalents for PC-DAG and DGTS combined with a dominance by the saturated and monounsaturated fatty acids $\mathrm{C}_{14}, \mathrm{C}_{16}$ and $\mathrm{C}_{18}$ (Table S5) support a shift from eukaryotic to bacterial sources. This suggests that the diverse proteobacteria in the upper OMZ may biosynthesize non- 
phosphorus substitute IPLs. 1G-DAG or DGTS are known to replace phospholipids, primarily PE-DAG and PC-DAG under phosphorus-limited growth (Geske et al., 2012; Carini et al., 2015; Sebastian et al., 2016; Yao et al., 2015), including at the phosphate concentrations of 2 to $2.5 \mu \mathrm{M}$ in the upper OMZ. Sulfate-reducing proteobacteria, which comprise up to $10 \%$ of the total bacteria in the ETNP (Podlaska et al., 2012), may be candidate organisms for this phospholipidto-glycolipid replacement (Bosak et al., 2016). Structures of minor IPLs, AL-I and AL-II were not fully elucidated (see Fig. S6), and their origins remain uncertain. PME- and PDME-DAG, DPG, 1G-CER and 1G-OH-CER within the upper OMZ are consistent with previous reports of their production by (unidentified) bacteria near redox boundaries in other stratified water bodies (Schubotz et al., 2009; Wakeham et al., 2012).

Archaeal IPLs with glycosidic head groups and tetraether core structures (1G- and 2G-GDGT) comprised a greater proportion of the overall IPL pool within the upper OMZ than in surface waters. An analysis of these same samples by Xie et al. (2014) first reported that concentrations of glycosidic GDGTs peak in the ETNP roughly at depths where nitrite maxima are observed. IP-GDGTs with the hexosephosphate-hexose (HPH) head groups and the core GDGT crenarchaeol (Fig. S4) of thaumarchaeota (Schouten et al., 2008; Elling et al., 2017) were most abundant at depths of nitrate maxima at all ETNP stations, as they are in other oxygen-deficient water columns (e.g., Pitcher et al., 2011; Lengger et al., 2012; Schouten et al., 2012; Sollai et al., 2015), although they were present at greater depths in the ENTP as well. The microbial enumerations by Podlaska et al. (2012) had shown previously that thaumarchaeota (referred to as crenarchaeota) and Euryarchaeota constitute almost equal amounts to $<10 \%$ of total cell number in the upper OMZ of the ETNP. It is also possible that uncultured marine Group II Euryarchaeota are additional sources for glycosidic GDGTs, as has been suggested previously (Lincoln et al., 2014; Zhu et al., 2016).

\subsubsection{Core OMZ and deep oxycline}

IPL distributions in the core OMZ and at the deep oxycline of the ETNP that were notably different from the oxic zone and the upper OMZ are consistent with in situ microbial origins. We choose to discuss the core OMZ and deep oxycline together, because although oxygen concentrations are beginning to rise in the deep oxycline, IPL compositions in both zones are similar and likely reflect similar biogeochemical sources. Phospholipid abundance at all stations generally increased to over $50 \%$ (except for Station 8) at the expense of glycolipids. PE and PG-DAG are the most abundant phospholipids in the core OMZ, along with PC-DAG, PE- and PC-AEG, and DPG. PME and PDME-DAG are all common lipids in $\alpha$-, $\gamma$ - and some $\beta$-proteobacteria (Oliver and Colwell, 1973; Goldfine, 1984) that are present in the
OMZ (Podlaska et al., 2012). Changes in phospholipid chain length and number of double bond equivalents further support in situ IPL production (Fig. 5). Fatty-acid combinations for phospholipids were dominated by saturated $\mathrm{C}_{14: 0}, \mathrm{C}_{15: 0}$ and $\mathrm{C}_{16: 0}$ and monounsaturated $\mathrm{C}_{16: 0} \mathrm{C}_{17}$ and $\mathrm{C}_{18: 0}$ (Table S5); PUFA is generally of reduced abundance, and oddnumbered fatty acids increased in proportion. In the case of PUFA, even though it may be biosynthesized by piezophilic aerobic deep-sea bacteria (DeLong and Yayanos, 1986; Fang et al., 2003; Valentine and Valentine, 2004), either the microaerophilic bacteria in the deep OMZ of the ETNP do not produce PUFA or these labile fatty acids are rapidly degraded in situ (DeBaar et al., 1983; Prahl et al., 1984; Neal et al., 1986).

Among glycolipids, 1G-DAG was most abundant at the deep OMZ/oxycline at Stations 1 and 8; here 1G-DAG abundance actually increases over that of shallower depths. The carbon number and number of double bond equivalents for glycolipids are again distinct from the surface waters, on average with shorter chain lengths of one to two carbon atoms and one to three fewer double bonds (Fig. 5), supporting the notion that at least some of these glycolipids are biosynthesized in situ and are not simply exported from the surface waters. In particular, SQ-DAG in the core OMZ/oxycline contained odd-carbon numbered fatty acids (e.g., $\mathrm{C}_{15: 0} / \mathrm{C}_{16: 0}$ and $\mathrm{C}_{14: 0} / \mathrm{C}_{15: 0}$ ) different from the cyanobacterial SQ-DAG in surface waters (Table S5). Some Gram-positive bacillus and firmicutes biosynthesize 1G, 2G- and SQ-DAG (Hölzl and Dörmann, 2007), and 1G-, 2G- and SQ-DAG in deeply buried Wadden Sea sediments are attributed to anaerobic bacteria (Seidel et al., 2012). However, Gram-positive bacteria are generally not abundant in seawater.

The core OMZ/deep oxycline are particularly enriched in archaeal GDGT, notably 1G-GDGT and HPH-GDGT, predominantly with GDGT-0 and crenarchaeol as core lipids (Fig. S4). At Stations 1 and 8 where sampling penetrated below $\sim 800 \mathrm{~m}$ depth, 1G-GDGT and HPH-GDGT constitute up to $\sim 60 \%$ and $\sim 22 \%$, respectively, of total IPL. Significantly, the elevated abundances of 1G-GDGT and HPHGDGT at the bottoms of the sampling depth profiles in the deep oxycline of Stations 1 and 8 correspond to depths at which ammonium concentrations are higher than at depths shallower in the core OMZ (Fig. 2). Remineralization at the deep oxycline might provide additional ammonium to drive the ammonium oxidation of thaumarchaeota and the production of archaeal IPLs.

\subsubsection{Factors influencing IPL distribution in the ENTP}

\subsubsection{Factors affecting structural diversity of the core lipid composition}

IPLs in the ETNP display considerable diversity not only in the head group but also in core lipid types, from diacylglycerol lipids with a varying number of carbon atoms (likely 
chain lengths) and zero to multiple double bond equivalents (likely reflecting the number of unsaturations), with or without hydroxylations to mixed ether/ester glycerolipids, sphingolipids and ornithine lipids. Statistical analysis aids in illuminating influences of environmental factors and microbial community structure on the lipid composition in the water column of the ETNP. Changes in core alkyl lipid chain length and the degree of unsaturation are often associated with temperature (Neidleman, 1987), even at the range of temperatures of the ETNP water column. However, NMDS analysis did not yield any strong correlations between temperature and number of carbon atoms in the side chains or double bond equivalents of the major IPL classes $\left(r^{2}<0.02\right.$, Table S6), nor with other environmental parameters $\left(r^{2}<0.3\right.$, Table S6). Instead, changing biological sources may play a decisive role in determining the number of carbon atoms and double bond equivalents in the ETNP. For instance, longchain PUFAs in surface waters are mainly synthesized by phytoplankton, while in deeper waters, some bacteria may biosynthesize these PUFAs. The degree of hydroxylation in the acyl side chains also did not show any clear link to specific environmental factors, although both $1 \mathrm{GOH}-\mathrm{CER}$ and OH-DGTS had negative loadings on the NMDS- 2 axis, indicating a higher abundance of these compounds in oxic samples. It is possible that hydroxylated IPLs play a role during oxidative stress and/or are involved in other defense mechanisms (Kato et al., 1984; Andreou et al., 2009).

Mixed ether-acyl lipids have been reported in various oceanic settings (Hernandez-Sanchez et al., 2014). In our study, there was no noticeable correlation between PE- and PC-AEG and depth or oxygen concentrations (Fig. 6). Ornithine lipids were strongly negatively loaded on the NMDS1 axis, but none of the measured environmental parameters could account for this negative loading (Fig. 6). Therefore, it remains unclear which factor(s) ultimately determine their distribution. Likewise, there were no significant correlations between the sphingolipid 1G-CER and any environmental parameter. Since ether-acyl lipids, ornithine lipids and sphingolipids play many functional roles in biological systems, their variable distributions within the water column most likely reflect the diversity of microbes inhabiting the dynamic oxygen regime of the ETNP.

\subsubsection{Factors influencing head-group composition}

The NDS analysis of normalized IPL composition and quantitative microbial data (abundance of $\alpha-, \beta-, \gamma-$ and $\varepsilon$ proteobacteria; sulfate-reducing bacteria $\delta$-proteobacteria; planctomycetes; and crenarchaeota, including thaumarchaeota and euryarchaeota) did not yield any high goodnessof-fit statistic $\left(r^{2}<0.3\right.$; Table S6) that would clearly delineate specific prokaryotic sources for the various IPL. This absence of statistical correlation would result if neither the IPL compositions of SPM nor the structure and lipid composition of the prokaryotic community were sufficiently unique to strongly distinguish the biogeochemical zones. Indeed, although there are depth-related differences in the IPL composition of SPM and prokaryotic community, there is considerable overlap. Therefore, instead of trying to elucidate specific IPL sources, here we query the affect the environmental factors such as temperature, nutrient or oxygen concentrations may have on the IPL compositions in the ENTP, and by analogy, to natural marine settings in general. Most the major and minor glycolipids were loaded negatively on the NMDS2 axis, as were oxygen, fluorescence, $\mathrm{Chl} \alpha$, POC and TN (Fig. 6). A notable exception was $1 \mathrm{G}-\mathrm{DAG}$, which had only a slightly negative loading on the NMDS-2 axis. These relationships (loadings) roughly reflect the vertical distribution of IPLs in the water column of the ETNP. Glycolipids, particularly 2G-DAG and SQ-DAG, were most abundant in the euphotic oxic zone characterized by high oxygen concentration and moderate primary productivity, which was dominated by phytoplankton, primarily cyanobacteria (high POC, $\mathrm{TN}$ and elevated $\mathrm{Chl} \alpha$ and fluorescence). Spearman's rank order correlations confirm these observations, including the lack of significant correlations between 1G-DAG and depth or any other environmental parameter. One explanation is that 1G-DAG originates from assorted sources throughout the water column independent of any single environmental variable. Similarly, PC-DAG, PG-DAG and DGTS did not correlate with any of the tested environmental variables, because their compositions are relatively homogeneous across all biogeochemical zones. PE-, PME- and PDME-DAG, and DPG, on the other hand, became more prevalent within the core $\mathrm{OMZ}$ and at deeper depths where oxygen concentrations decrease and nutrient $\left(\mathrm{NO}_{3}^{-}\right.$and $\left.\mathrm{PO}_{4}^{3-}\right)$ concentrations were elevated due to organic matter remineralization; this gave positive loadings with these environmental parameters on the NDMS2 axis. Archaeal IPLs showed positive loadings on the NMDS-2 axis, consistent with the increasing importance of archaeal abundance with depth and at reduced oxygen concentrations.

\subsubsection{Links between substitute lipid ratios and nutrient concentrations}

SQ-DAG and PC-DAG are often the most abundant respective glycolipids and phospholipids in the ocean's surface (Popendorf et al., 2011a, b), including the eastern tropical South Pacific (Van Mooy and Fredricks, 2010). The abundance of SQ-DAG in the surface waters of the ETNP $(18 \%$ $50 \%$ of total IPL) is thus not unusual. In the ETNP, however, PC-DAG was comparably minor $(3 \%-13 \%$ of total IPL). Instead, DGTS was abundant at some stations, up to $\sim 20 \%$ of major IPL at Station 5. SQ-DAG and DGTS serve similar biochemical functions as the phospholipids PG-DAG and PC-DAG, respectively, due to similar ionic charges at physiological $\mathrm{pH}$. The former may be preferentially biosynthesized by phytoplankton and some bacteria as substitute lipids for PG-DAG and PC-DAG when 
starved of phosphate (Benning, 1993; Van Mooy et al., 2006, 2009). Likewise, 1G-DAG, glycuronic acid diacylglycerol (GADG) and ornithine lipids may substitute for PE-DAG in marine bacteria (e.g., chemoheterotrophic $\alpha$-proteobacteria of the SAR11 clade of Pelagibacter sp. - Carini et al., 2015; the sulfate reducing bacterium, Desulfovibrio alaskensis - Bosak et al., 2016). In oligotrophic surface waters of the Sargasso Sea $\left(\mathrm{PO}_{4}^{3-}<10 \mathrm{nM}\right)$, ratios of SQ-DAG: PGDAG and DGTS : PC-DAG are high (4 to 13) compared to the same ratios (3) in the phosphate-replete South Pacific $\left(\mathrm{PO}_{4}^{3-}>100 \mathrm{nM}\right)$, consistent with cyanobacteria synthesizing phosphorus-free substitute lipids to maintain growth in response to phosphorus deprivation (Van Mooy et al., 2009). At the ETNP, SQ-DAG: PG-DAG ratios ranged between 1 and 10 within the upper $100-200 \mathrm{~m}$ along the transect and were $<1$ deeper into the OMZ (Fig. 3). DGTS : PC-DAG ratios in the ETNP were quite variable, ranging between 0.4 and 2.4 at most depths, but with notable spikes $(>30)$ within the oxic zone at Station 5, within the upper core OMZ at Stations 2 and 8, and in the lower portion of the core OMZ at Station 8. 1G-DAG: PE-DAG ratios where highly variable $(0.2$ to 945$)$ and were highest within the upper OMZ at Stations 2, 5 and 8 and within the deep oxycline at Station 8, where 1G-DAG: PE ratios range between 290 and 945 (Fig. 3). To test the substitute lipid hypothesis for the ETNP, we performed a Spearman's rank order correlation analysis of known substitute lipid ratios as well as ratios of total aminolipid (AL) to phospholipid (PL) and total glycolipid (GL) to PL with nutrient concentrations and other environmental parameters. Only SQ-DAG : PG-DAG was significantly correlated with phosphate $(-0.56, p<0.001)$ but also correlated with other parameters, such as depth $(-0.76$, $p<0.001)$ and oxygen concentration $(0.58, p<0.001)$. These correlations reflect the elevated SQ-DAG: PG-DAG ratios (2-8) in the surface waters and upper OMZ (Fig. 3) and support the notion that SQ-DAG might serve as a substitute lipid in both surface waters and the OMZ when phosphate concentrations are in the low micromolar range $(\sim 0.1-0.4 \mu \mathrm{M}$ in surface waters; $\sim 2-3.5 \mu \mathrm{M}$ in the OMZ). Other proposed substitute lipid ratios, DGTS : PC-DAG (Van Mooy et al., 2009) and 1G-DAG : PE-DAG (Carini et al., 2015), did not correlate with nutrient concentrations in the water column of the ETNP but rather showed highly variable distributions. Similarly, AL: PL ratios did not exhibit strong relationships with any environmental parameter, and GL:PL ratios showed similar but less-pronounced trends than SQDAG : PG-DAG ratios. Overall, we observed no correlation between these substitute lipid ratios and phosphate concentration in the ETNP. We propose that non-phosphorus IPLs within the OMZ of the ETNP originate from bacteria growing under low micromolar concentrations of phosphate. Indeed, the culture experiments of Bosak et al. (2016) demonstrated that the sulfate reducer, Desulfovibrio alaskensis, begins to replace most of its membrane phospholipids with $1 \mathrm{G}$ -
DAG, glycuronic acid diacylglycerol and ornithine lipids, even at phosphate concentrations as high as $20 \mu \mathrm{M}$.

\section{Conclusions}

The water column of the ETNP is characterized by a diverse suite of intact polar lipids. IPL distributions reflect the dynamic nature of the biological community in the ETNP, with light and oxygen as primary determinants, from fully oxygenated euphotic surface waters to an aphotic strong oxygen minimum zone at mid depth. The highest concentrations of IPLs $\left(250-1500 \mathrm{ng} \mathrm{L}^{-1}\right)$ in the oxygenated surfacewater zone result from abundant phototrophic eukaryotic and cyanobacterial sources above the OMZ. Secondary peaks in IPL concentration $\left(12-56 \mathrm{ng} \mathrm{L}^{-1}\right)$ within the core of the OMZ mirror elevated abundances of heterotrophic and chemoautotrophic bacteria and archaea under low-oxygen conditions. Glycolipids derived from photoautotrophs generally accounted for more than $50 \%$ of total IPLs in the euphotic zone ( $<200 \mathrm{~m}$, oxic and upper OMZ zones), but bacterial phospholipids were more abundant (average. $40 \%$ ) in the OMZ and deep oxycline layers. Archaeal GDGTs were abundant within the OMZ and deep oxycline, consistent with elevated archaeal cell abundances there. Variations in major fatty-acid constituents within IPL classes with acyl core moieties show that biological source(s) for the different IPL were distinct in each depth or oxygen-content horizon. Nevertheless, microbial sources for many of the detected lipids remain unclear; therefore, the potentially unique ecophysiological adaptations these lipids may represent remain to be explored.

The presence of the glycolipid, monoglycosyl diacylglycerol (1G-DAG) and the betaine lipid, diacylglyceryl homoserine (DGTS), both with varying fatty-acid compositions and within all biogeochemical zones, especially the OMZ, indicates that these canonical phototrophic markers are not only biosynthesized in surface waters, but they may indeed be produced in the aphotic water column and by a much larger host of organisms than previously thought. Since 1GDAG and DGTS can be biosynthesized by various bacteria to replace phospholipids under phosphorus limited growth, we suggest that they serve as non-phosphorus substitute lipids for some microorganisms in the OMZ. The presence of these substitute lipids in micromolar concentrations of phosphate of the ETNP suggests that the paradigm of substitute lipid biosynthesis being restricted to the oligotrophic surface ocean depleted of $\mathrm{PO}_{4}^{3-}$ may need to be re-evaluated.

Data availability. Data will be deposited at the PANGAEA data base (https://www.pangaea.de) after publication and is also available in table format in the Supplement of this manuscript. 
Supplement. The supplement related to this article is available online at: https://doi.org/10.5194/bg-15-6481-2018-supplement.

Author contributions. SGW collected the samples. SGW, FS and KUH designed the study. SX and FS measured and processed the data. JSL and FS performed statistical analyses. FS and SGW wrote the paper with input from SX, KUH and JSL.

Competing interests. The authors declare that they have no conflict of interest.

Acknowledgements. We are grateful to the captain and the crew of R/V Seward Johnson, to Kendra Daly and Karen Wishner as co-chief scientists, and to the U.S. National Science Foundation for supporting the cruise. Heidi Albrecht, Brady Olson and Sennai Habtes helped with PM sampling. We thank Kent Fanning and Robert Masserini (University of South Florida) for providing their nutrient results, Charles Flagg (Stony Brook) for processing CTD hydrographic data, Jay Brandes and Mary Richards (Skidaway Institute) for conducting the POC and TN analyses, Brady Olson and Kendra Daly (University of South Florida) for providing shipboard $\mathrm{Chl} a$ analyses, and Giacomo diTullio (College of Charleston) for conducting HPLC analyses of pigments. Lab supplies and the analytical infrastructure for lipid analyses was funded by the Deutsche Forschungsgemeinschaft (DFG, Germany) through the Cluster of Excellence/Research Center MARUM. The UHPLC-QTOF instrument was granted by the DFG, Germany through grants Inst 144/300-1. Sitan Xie was funded by the China Scholarship Council, Florence Schubotz by the Zentrale Forschungsförderung of the University of Bremen, and the U.S. National Science Foundation grant OCE-0550654 to Stuart G. Wakeham supported this project. Stuart G. Wakeham also acknowledges a Fellowship from the Hanse-Wissenschaftskolleg (Hanse Institute for Advanced Studies) in Delmenhorst, Germany.

The article processing charges for this open-access

publication were covered by the University of Bremen.

Edited by: Markus Kienast

Reviewed by: Nicole J. Bale and two anonymous referees

\section{References}

Andreou, A., Brodhun, F., and Feussner, I.: Biosynthesis of oxylipins in non-mammals, Progr. Lip. Res., 48, 148-170, 2009.

Bale, N. J., Hopmans, E. C., Schoon, P. L., de Kluijver, A., Downing, J. A., Middelburg, J. J., Sinninghe Damsté, J. S., and Schouten, S.: Impact of trophic state on the distribution of intact polar lipids in surface waters of lakes, Limnol. Oceanogr., 61, 1065-1077, 2016.

Basse, A., Zhu, C., Versteegh, G. J. M., Fischer, G., Hinrichs, K.-U., and Mollenhauer, G.: Distribution of intact and core tetraether lipids in water column profiles of suspended particulate matter off Cape Blank, NW Africa, Org. Geochem., 72, 1-13, 2014.
Benning, C., Beatty, J. T., Prince, R. C., and Somerville, C. R.: The sulfolipid sulfoquinovosyldiacylglycerol is not required for photosynthetic electron transport in Rhodobacter sphaeroides but enhances growth under phosphate limitation, P. Natl. Acad. Sci. USA, 90, 1561-1565, 1993.

Bianchi, M., Marty, D., Teyssié, J.-L., and Fowler, S. W.: Strictly aerobic and anaerobic bacteria associated with sinking particulate matter and zooplankton fecal pellets, Mar. Ecol. Press Ser., 88, 55-60, 1992.

Bosak, T., Schubotz, F., de Santiago-Torio, A., Kuehl, J. V., Carlson, H. K., Watson, N., Daye, M., Summons, R. E., Arkin, A. P., and Deutschbauer, A. M.: System-wide adaptations of Desulfovibrio alaskensis G20 to phosphate-limited conditions, PLoS ONE, 11, e0168719, https://doi.org/10.1371/journal.pone.0168719, 2016.

Brandsma, J., Hopmans, E. C., Philippart, C. J. M., Veldhuis, M. J. W., Schouten, S., and Sinninghe Damsté, J. S.: Low temporal variation in the intact polar lipid composition of North Sea coastal marine water reveals limited chemotaxonomic value, Biogeosciences, 9, 1073-1084, https://doi.org/10.5194/bg-91073-2012, 2012.

Brett, M. T. and Müller-Navarra, D. C.: The role of highly unsaturated fatty acids in aquatic foodweb processes, Freshw. Biol., 38, 483-499, 1997.

Carini, P., Van Mooy, B. A. S., Thrash, J. C., White, A., Zhao, Y., Campbell, E. O., Fredricks, H. F., and Giovannoni, S. J.: SAR11 lipid renovation in response to phosphate starvation, $\mathrm{P}$. Natl. Acad. Sci. USA, 112, 7767-7772, 2015.

Carolan, M. T., Smith, J. M., and Beman, J. M.: Transcriptomic evidence for microbial sulfur cycling in the eastern tropical North Pacific oxygen minimum zone, Front. Microbiol., 6, 334, https://doi.org/10.3389/fmicb.2015.00334, 2015.

Cass, C. J. and Daly, K. L.: Ecological characteristics of eucalanoid copepods of the eastern tropical North Pacific Ocean: Adaptations for life within a low oxygen system, J. Exp. Mar. Biol. Ecol., 468, 118-129, 2015.

Cavan, E. L., Trimmer, M., Shelley, F., and Sanders, R.: Remineralization of particulate organic carbon in an ocean oxygen minimum zone, Nat. Commun., 8, 14847, https://doi.org/10.1038/ncomms14847, 2016.

Codispoti, L. A. and Richards, F. A.: An analysis of the horizontal regime of denitrification in the eastern tropical North Pacific, Limnol. Oceanogr., 21, 379-388, 1976.

DeBaar, H. J. W., Farrington, J. W., and Wakeham, S. G.: Vertical flux of fatty acids in the North Atlantic Ocean, J. Mar. Res., 41, 19-41, 1983.

DeLong, E. F. and Yayanos, A.: Biochemical function and ecological significance of novel bacterial lipids in deep-sea procaryotes, Appl. Environ. Mirobiol., 51, 730-737, 1986.

Dembitsky, V.: Betaine ether-linked glycerolipids: Chemistry and biology, Progr. Lip. Res., 35, 1-51, 1996.

Diervo, A. J. and Reynolds, J. W.: Phospholipid composition and cardiolipin synthesis in fermentative and nonfermentative marine bacteria, J. Bacteriol., 123, 294-301, 1975.

DiTullio, G. and Geesey, M. E.: Photosynthetic Pigments in Marine Algae and Bacteria. in: Encyclopedia of Environmental Microbiology, edited by: Bitton, G., vol. 5, 2453-2470, Wiley, New York, NY, USA, 2002.

Elling, F. J., Könneke, M., Mußmann, M., Greve, A., and Hinrichs, K.-U.: Influence of temperature, $\mathrm{pH}$, and salinity on mem- 
brane lipid composition and TEX86 of marine planktonic thaumarchaeal isolates, Geochim. Cosmochim. Acta, 171, 238-255, 2015.

Elling, F. J., Könneke, M., Nicol, G. W., Stieglmeier, M., Bayer, B., Spieck, E., La Torre, De J. R., Becker, K. W., Thomm, M., Prosser, J. I., Herndl, G. J., Schleper, C., and Hinrichs, K.-U.: Chemotaxonomic characterisation of the thaumarchaeal lipidome, Environ. Microbiol., 19, 2681-2700, https://doi.org/10.1111/1462-2920.13759, 2017.

Ertefai, T., Fisher, M., Fredricks, H., and Lipp, J.: Vertical distribution of microbial lipids and functional genes in chemically distinct layers of a highly polluted meromictic lake, Org. Geochem., 39, 1572-1588, 2008.

Exterkate, F. A. and Veerkamp, J. H.: Biochemical changes in Bifidobacterium bifidum var. Pennsylvanicus after cell wall inhibition. I. Composition of lipids, Biochim. Biophys. Acta, 176, 65-77, 1969.

Fang, J., Kato, C., Sato, T., Chan, O., and McKay, D.: Biosynthesis and dietary uptake of polyunsaturated fatty acids by piezophilic bacteria, Comp. Biochem. Phys. B, 137, 455-446, 2004.

Fiedler, P. C. and Talley, L. D.: Hydrography of the eastern tropical Pacific: A review, Progr. Oceanogr., 69, 143-180, 2006.

Franck, V. M., Smith, G. J., Bruland, K. W., and Brzezinski, M. A.: Comparison of size-dependent carbon, nitrate and silicic acid uptake rates in high- and low-iron waters, Limnol. Oceanogr., 50, 825-838, 2005.

Geiger, O., Röhrs, V., Weissenmayer, B., Finan, T. M., and ThomasOates, J. E.: The regulator gene phoB mediates phosphate stress-controlled synthesis of the membrane lipid diacylglyceryl$\mathrm{N}, \mathrm{N}, \mathrm{N}$-trimethylhomoserine in Rhizobium (Sinorhizobium) meliloti, Mol. Microbiol., 32, 63-73, 1999.

Geske, T., Dorp vom, K., Dörmann, P., and Hölzl, G.: Accumulation of glycolipids and other non-phosphorous lipids in Agrobacterium tumefaciens grown under phosphate deprivation, Glycobiol., 23, 69-80, 2012.

Goericke, R., Olson, R. J., and Shalapyonok, A.: A novel niche for Prochlorococcus sp. in low-light suboxic environments in the Arabian Sea and the Eastern Tropical North Pacific, Deep-Sea Res. Pt. I, 47, 1183-1205, 2000.

Goldfine, H.: Bacterial membranes and lipid packing theory, J. Lip. Res., 25, 1501-1507, 1984.

Goldfine, H. and Ellis, M. E.: N-methyl groups in bacterial lipids, J. Bacteriol., 87, 8-15, 1964.

Gruber, N.: The marine nitrogen cycle: overview and challenges, in: Nitrogen in the marine environment, edited by: Capone, D. G., Bronk, D. A., Mulholland, M. R., and Carpenter, E. J., Burlington, Academic, MA, USA, 1-50, 2008.

Harvey, R. H., Fallon, R. D., and Patton, J. S.: The effect of organic matter and oxygen on the degradation of bacterial membrane lipids in marine sediments, Geochim. Cosmochim. Acta, 50, 795-804, 1986.

Hernandez-Sanchez, M. T., Homoky, W. B., and Pancost, R. D.: Occurrence of 1-O-monoalkyl glycerol ether lipids in ocean waters and sediment, Org. Geochem., 66, 1-13, 2014.

Hölzl, G. and Dörmann, P.: Structure and function of glycoglycerolipids in plants and bacteria, Progr. Lip. Res., 46, 225-243, 2007.

Hunter, J. E., Brandsma, J., Dymond, M. K., Koster, G., Moore, M., Postle, A. D., Mills, R. A., and Attard, G. S.:
Lipidomics of Thalassiosira pseudonana under phosphorus stress reveal underlying phospholipid substitution dynamics and novel diglycosylceramide substitutes, Appl. Environ. Microb., https://doi.org/10.1128/AEM.02034-17, 2018.

Kalvelage, T., Lavik, G., Jensen, M. M., Revsbech, N. P., Löscher, C., Schunck, H., Desai, D. K., Hauss, H., Kiko, R., Holtappels, M., LaRoche, J., Schmitz, R. A., Graco, M. I., and Kuypers, M. M. M: Aerobic microbial respiration in oceanic oxygen minimum zones, PLoS ONE, 10, e0133526, https://doi.org/10.1371/journal.pone.0133526, 2015.

Karstensen, J., Stramma, L., and Visbeck, M.: Oxygen minimum zones in the eastern tropical Atlantic and Pacific oceans, Progr. Oceanogr., 77, 331-350, 2008.

Kato, T., Yamaguchi, Y., Hirano, T., and Yokoyama, T.: Unsaturated hydroxy fatty acids, the self defensive substances in rice plant against rice blast disease, Chem. Lett., 409-412, 1984.

Keeling, R. F., Körtzinger, A., and Gruber, N.: Ocean deoxygenation in a warming world, Annu. Rev. Marine Sci., 2, 199-229, 2010.

Kharbush, J. J., Allen, A. E., Moustafa, A., Dorrestein, P. C., and Aluwihare, L. I.: Intact polar diacylglycerol biomarker lipids isolated from suspended particulate organic matter accumulating in an ultraoligotrophic water column, Org. Geochem., 100, 29-41, 2016.

Lam, P. and Kuypers, M. M. M.: Microbial nitrogen cycling processes in oxygen minimum zones, Annu. Rev. Marine Sci., 3, 317-345, 2011.

Landry, M. R., Selph, K. E., Taylor, A. G., Décima, M., Balch, W. M., and Bidigare, R. R.: Phytoplankton growth, grazing and production balances in the HNLC equatorial Pacific, Deep-Sea Res. Pt. I, 58, 524-535, 2011.

Lavín, M. F., Fiedler, P. C., Amador, J. A., Balance, L. T., FärberLorda, J., and Mestas-Nuñez, A. M.: A review of eastern tropical Pacific oceanography: Summary, Progr. Oceanogr., 69, 391-398, 2006.

Lee, C. and Cronin, C.: Particulate amino acids in the sea: Effects of primary productivity and biological decomposition, J. Mar. Res., 42, 1075-1097, 1984.

Lehninger, A. L.: Oxidation of fatty acids, in: Biochemistry, Worth, New York, 417-432, 1970.

Lengger, S. K., Hopmans, E. C., Sinninghe Damsté, J. S., and Schouten, S.: Comparison of extraction and work up techniques for analysis of core and intact polar tetraether lipids from sedimentary environments, Org. Geochem., 47, 34-40, 2012.

Lin, X., Wakeham, S. G., Putnam, I. F., Astor, Y. M., Scranton, M. I., Chistoserdov, A. Y., and Taylor, G. T.: Comparison of vertical distributions of prokaryotic assemblages in the anoxic Cariaco Basin and Black Sea by use of fluorescence in situ hybridization, Appl. Environ. Microbiol., 72, 2679-2690, 2006.

Lincoln, S. A., Wai, B., Eppley, J. M., Church, M. J., Summons, R. E., and DeLong, E. F.: Planktonic Euryarchaeota are a significant source of archaeal tetraether lipids in the ocean, P. Natl. Acad. Sci. USA, 111, 9858-9863, 2014.

Lynch, D. V. and Dunn, T. M.: An introduction to plant sphingolipids and a review of recent advances in understanding their metabolism and function, New Phytol., 161, 677-702, 2004.

Ma, Y., Zeng, Y., Jiao, N., Shi, Y., and Hong, N.: Vertical distribution and phylogenetic composition of bacteria in the Eastern 
Tropical North Pacific Ocean, Microbiol. Res., 164, 624-663, 2009

Maas, A. E., Frazar, S. L., Outram, D. M., Seibel, B. A., and Wishner, K. F.: Fine-scale vertical distributions of macroplankton and micronekton in the Eastern Tropical North Pacific in association with an oxygen minimum zone, J. Plankt. Res., 36, 1557-1575, 2014.

Martin, J. H., Knauer, G. A., Karl, D. M., and Broenkow, W. W.: VERTEX: carbon cycling in the northeast Pacific, Deep-Sea Res., 34, 267-285, 1987.

Matos, A. R. and Pham-Thi, A.-T.: Lipid deacylating enzymes in plants: Old activities, new genes, Plant Physiol. Bioch., 47, 491503, 2009.

Meador, T. B., Gagen, E. J., Loscar, M. E., Goldhammer, T., Yoshinaga, M. Y., Wendt, J., Thomm, M., and Hinrichs, K.U.: Thermococcus kodakarensis modulates its polar membrane lipids and elemental composition according to growth state and phosphate availability, Front. Microbiol., 5, 1-13, https://doi.org/10.3389/fmicb.2014.00010, 2014.

Mileykovskaya, E. and Dowhan, W.: Cardiolipin membrane domains in prokaryotes and eukaryotes, Biochim. Biophys. Acta, 1788, 2084-2091, 2009.

Morita, Y. S., Yamaryo-Botte, Y., and Miyanagi, K.: Stress-induced synthesis of phosphatidylinositol 3-phosphate in mycobacteria, J. Biol. Chem. 285, 16643-16650, 2010.

Neal, A. C., Prahl, F. G., Eglinton, G., O’Hara, S. C. M., and Corner, E. D. S.: Lipid changes during a planktonic feeding sequence involving unicellular algae, Elminius Nauplii and Adult Calanus, J. Mar. Biol. Assoc. UK, 66, 1-13, 1986.

Neidleman, S. L.: Effects of temperature on lipid unsaturation, Biotechnol. Genet. Eng. Rev., 5, 245-268, 1987.

Okuyama, H., Kogame, K., and Takeda, S.: Phylogenetic significance of the limited distribution of octadecapentaenoic acid in prymnesiophytes and photosynthetic dinoflagellates, Proc. NIPR Symp. Polar Biol., 6, 21-26, 1993.

Oliver, J. D. and Colwell, R. R.: Extractable lipids of gram-negative marine bacteria: Phospholipid composition, J. Bacteriol., 114, 897-908, 1973.

Olson, M. B. and Daly, K. L.: Micro-grazer biomass, composition and distribution across prey resource and dissolved oxygen gradients in the far eastern tropical north Pacific Ocean, Deep-Sea Res. Pt. I, 75, 28-38, 2014.

Parsons, T. R., Takahashi, M., and Hargrave, B. (Eds.): Biological Oceanographic Processes, 3rd edn., Pergamon Press, NY, 1984.

Paulmier, A. and Ruiz-Pino, D.: Oxygen minimum zones (OMZs) in the modern ocean, Progr. Oceanogr., 80, 113-128, 2009.

Pennington, J. T., Mahoney, K. L., Kuwahara, V. S., Kolber, D. D., Clienes, R., and Chavez, F. P.: Primary production in the eastern tropical Pacific: A review, Progr. Oceanogr., 69, 285-317, 2006.

Pitcher, A., Villanueva, L., Hopmans, E. C., Schouten, S., Reichart, G.-J., and Sinninghe Damsté, J. S.: Niche segregation of ammonia-oxidizing archaea and anammox bacteria in the Arabian Sea oxygen minimum zone, ISME J., 5, 1896-1904, 2011.

Podlaska, A., Wakeham, S. G., Fanning, K. A., and Taylor, G. T.: Microbial community structure and productivity in the oxygen minimum zone of the eastern tropical North Pacific, Deep-Sea Res. Pt. I, 66, 77-89, 2012.
Popendorf, K., Lomas, M., and Van Mooy, B.: Microbial sources of intact polar diacylglycerolipids in the Western North Atlantic Ocean, Org. Geochem., 42, 803-811, 2011 a.

Popendorf, K. J., Tanaka, T., Pujo-Pay, M., Lagaria, A., Courties, C., Conan, P., Oriol, L., Sofen, L. E., Moutin, T., and Van Mooy, B. A. S.: Gradients in intact polar diacylglycerolipids across the Mediterranean Sea are related to phosphate availability, Biogeosciences, 8, 3733-3745, https://doi.org/10.5194/bg-8-37332011, 2011b.

Prahl, F. G., Eglinton, G., Corner, E. D. S., O'Hara, D. C. M., and Forsberg, T. E. V.: Changes in plant lipids during passage through the gut of Calanus, J. Mar. Biol. Assoc. UK, 64, 317-334, 1984.

Rabinowitz, G. B.: An introduction to nonmetric multidimensional scaling, Amer. J. Polit. Sci., 19, 343-90, 1975.

Rappé, M. S., Vergin, K., and Giovannoni, S. J.: Phylogenetic comparisons of a coastal bacterioplankton community with its counterparts in open ocean and freshwater systems, FEMS Microbiol. Ecol., 33, 219-232, 2000.

Rojas-Jiménez, K., Sohlenkamp, C., Geiger, O., Martínez-Romero, E., Werner, D., and Vinuesa, P.: A ClC chloride channel homolog and ornithine-containing membrane lipids of rhizobium tropici CIAT899 are involved in symbiotic efficiency and acid tolerance, Mol. Plant Microbe In., 18, 1175-1185, 2005.

Rush, D., Wakeham, S. G., Hopmans, E. C., Schouten, S., and Damsté, J. S. S.: Biomarker evidence for anammox in the oxygen minimum zone of the Eastern Tropical North Pacific, Org. Geochem., 53, 80-87, 2012.

Rütters, H., Sass, H., Cypionka, H., and Rullkötter, J.: Monoalkylether phospholipids in the sulfate-reducing bacteria Desulfosarcina variabilis and Desulforhabdus amnigenus, Arch. Microbiol., 176, 435-442, 2001.

Schouten, S., Hopmans, E. C., Baas, M., Boumann, H., Standfest, S., Könneke, M., Stahl, D. A., and Sinninghe Damsté, J. S.: Intact membrane lipids of "Candidatus Nitrosopumilus maritimus", a cultivated representative of the cosmopolitan mesophilic Group I crenarchaeota, Appl. Environ. Microb., 74, 2433-2440, 1008.

Schouten, S., Pitcher, A., Hopmans, E. C., Villanueva, L., Van Bleijswijk, J., and Sinninghe Damsté, J. S.: Intact polar and core glycerol dibiphytanyl glycerol tetraether lipids in the Arabian Sea oxygen minimum zone: I. Selective preservation and degradation in the water column and consequences for the TEX86, Geochim. Cosmochim. Acta, 98, 228-243, 2012.

Schubotz, F., Wakeham, S. G., Lipp, J., Fredricks, H. F., and Hinrichs, K.-U.: Detection of microbial biomass by intact polar membrane lipid analysis in the water column and surface sediments of the Black Sea, Environ. Microbiol., 11, 2720-2734, 2009.

Sebastian, M., Smith, A. F., González, J. M., Fredricks, H. F., Van Mooy, B., Koblížek, M., Brandsma, J., Koster, G., Mestre, M., Mostajir, B., Pitta, P., Postle, A. D., Sánchez, P., Gasol, J. M., Scanlan, D. J., and Chen, Y.: Lipid remodelling is a widespread strategy in marine heterotrophic bacteria upon phosphorus deficiency, ISME J., 10, 968-978, 2016.

Seibel, B. A.: Critical oxygen levels and metabolic suppression in oceanic oxygen minimum zones, J. Exp. Biol., 214, 326-336, 2011.

Seidel, M., Graue, J., Engelen, B., Köster, J., Sass, H., and Rullkötter, J.: Advection and diffusion determine vertical distribution of microbial communities in intertidal sediments as revealed 
by combined biogeochemical and molecular biological analysis, Org. Geochem., 52, 114-129, 2012.

Shanks, A. L. and Reeder, M. L.: Reducing microzones and sulfide production in marine snow, Mar. Ecol. Prog. Ser. 96, 43-47, 1993.

Siegenthaler, P.-A.: Molecular organization of acyl lipids in photosynthetic membranes of higher plants, in: Lipids in Photosynthesis, edited by: Siegenthaler, P.-A. and Murata, N., Kluwer Academic Publishers, Dordrecht, the Netherlands, 119-144, 1998.

Sohlenkamp, C., López-Lara, I. M., and Geiger, O.: Biosynthesis of phosphatidylcholine in bacteria, Progr. Lip. Res., 42, 115-162, 2003.

Sollai, M., Hopmans, E. C., Schouten, S., Keil, R. G., and Sinninghe Damsté, J. S.: Intact polar lipids of Thaumarchaeota and anammox bacteria as indicators of $\mathrm{N}$ cycling in the eastern tropical North Pacific oxygen-deficient zone, Biogeosciences, 12, 47254737, https://doi.org/10.5194/bg-12-4725-2015, 2015.

Stramma, L., Johnson, G. C., Sprintall, J., and Mohrholz, V.: Expanding Oxygen-Minimum Zones in the Tropical Oceans, Science, 320, 655-658, 2008.

Stramma, L., Schmidtko, S., Levin, L. A., and Johnson, G. C.: Ocean oxygen minima expansions and their biological impacts, Deep-Sea Res. Pt. I, 57, 587-595, 2010.

Sturt, H. F., Summons, R. E., Smith, K. E., Elvert, M., and Hinrichs, K.-U.: Intact polar membrane lipids in prokaryotes and sediments deciphered by high-performance liquid chromatography/electrospray ionization multistage mass spectrometry - new biomarkers for biogeochemistry and microbial ecology, Rapid Comm. Mass Spec., 18, 617-628, 2004.

Taylor, G. T., Iabichella, M., Ho, T.-Y., Scranton, M. I., Thunell, R. C., Muller-Karger, F., and Varela, R.: Chemoautotrophy in the redox transition zone of the Cariaco Basin: A significan midwater source of organic carbon production, Limol. Oceanogr., 46, 148 163,2001

Tiano, L., Garcia-Robledo, E., Dalsgaard, T., Devol, A. H., Ward, B. B., Ulloa, O., Canfield, D. E., and Revsbech, N. P.: Oxygen distribution and aerobic respiration in the north and south eastern tropical Pacific oxygen minimum zones, Deep-Sea Res. Pt. I, 94, 173-183, 2014.

Ulloa, O., Canfield, D., DeLong, E. F., Letelier, R. M., and Stewart, F. J.: Microbial oceanography of anoxic oxygen minimum zones, P. Natl. Acad. Sci. USA, 109, 15996-16003, 2012.

Valentine, R. C. and Valentine, D. L.: Omega-3 fatty acids in cellular membranes: a unified concept, Progr. Lip. Res., 43, 383-402, 2004

Van Mooy, B. A. S. and Fredricks, H. F.: Bacterial and eukaryotic intact polar lipids in the eastern subtropical South Pacific: Watercolumn distribution, planktonic sources, and fatty acid composition, Geochim. Cosmochim. Acta, 74, 6499-6516, 2010.

Van Mooy, B. A. S., Rocap, G., Fredricks, H. F., Evans, C. T., and Devol, A. H.: Sulfolipids dramatically decrease phosphorus demand by picocyanobacteria in oligotrophic marine environments, P. Natl. Acad. Sci. USA, 103, 8607-8612, 2006.

Van Mooy, B. A. S., Fredricks, H. F., Pedler, B. E., Dyhrman, S. T., Karl, D. M., Koblížek, M., Lomas, M. W., Mincer, T. J., Moore, L. R., Moutin, T., Rappé, M. S., and Webb, E. A.: Phytoplankton in the ocean use non-phosphorus lipids in response to phosphorus scarcity, Nature, 458, 69-72, 2009.
Vardi, A., Van Mooy, B. A. S., Fredricks, H. F., Popendorf, K. J., Ossolinski, J. E., Haramty, L., and Bidle, K. D.: Viral glycosphingolipids induce lytic infection and cell death in marine phytoplankton, Science, 326, 861-865, 2009.

Wada, H. and Murata, N.: Membrane Lipids in cyanobacteria, in: Lipids in Photosynthesis: Structure, Function and Genetics, edited by: Siegenthaler, P. and Murata, N., Kluwer Academic Publishers, Dordrecht, the Netherlands, 65-81, 1998.

Wakeham, S. G.: Steroid geochemistry in the oxygen minimum zone of the eastern tropical North Pacific Ocean, Geochim. Cosmochim. Acta, 51, 3051-3069, 1987.

Wakeham, S. G.: Reduction of stenols to stanols in particulate matter at oxic-anoxic boundaries in sea water, Nature, 342, 787-790, 1989.

Wakeham. S. G.: Monocarboxylic, dicarboxylic and hydroxy acids released by sequential treatments of suspended particles and sediments of the Black Sea, Org. Geochem., 30, 1059-1074, 1999.

Wakeham, S. G. and Canuel, E. A.: Organic geochemistry of particulate matter in the eastern tropical North Pacific Ocean: Implications for particle dynamics, J. Mar. Res., 46, 182-213, 1988.

Wakeham, S. G., Amann, R., Freeman, K. H., Hopmans, E. C., Jørgensen, B. B., Putnam, I. F., Schouten, S., Sinninghe Damsté, J. S., Talbot, H. M., and Woebken, D.: Microbial ecology of the stratified water column of the Black Sea as revealed by a comprehensive biomarker study, Org. Geochem., 38, 2070-2097, 2007.

Wakeham, S. G., Turich, C., Schubotz, F., Podlaska, A., Li, X. N., Varela, R., Astor, Y., Sáenz, J. P., Rush, D., Sinninghe Damsté, J. S., Summons, R. E., Scranton, M. I., Taylor, G. T., and Hinrichs, K.-U.: Biomarkers, chemistry and microbiology show chemoautotrophy in a multilayer chemocline in the Cariaco Basin, Deep Sea Res. Pt. I, 63, 133-156, 2012.

White, D. A., Widdicombe, C. E., Somerfield, P. J., Airs, R. L., Tarran, G. A., Maud, J. L., and Atkinson, A.: The combined effects of seasonal community succession and adaptive algal physiology on lipid profiles of coastal phytoplankton in the Western English Channel, Mar. Chem., 177, 6380-652, 2015.

Williams, R. L., Wakeham, S., McKinney, R., and Wishner, K. F.: Trophic ecology and vertical patterns of carbon and nitrogen stable isotopes in zooplankton from oxygen minimum zone regions, Deep-Sea Res. Pt. I, 90, 36-47, 2014.

Wishner, K. F., Outram, D. M., Seibel, B. A., Daly, K. L., and Williams, R. L.: Zooplankton in the eastern tropical north Pacific: Boundary effects of oxygen minimum zone expansion, Deep-Sea Res. Pt. I, 79, 122-140, 2013.

Woebken, D., Fuchs, B. M., Kuypers, M. M. M, and Aman, R.: Potential interactions of particle-associated anammox bacteria with bacterial and archaeal partners in the Namibian upwelling system, Appl. Environ. Microbiol., 73, 4648-4657, 2007.

Wörmer, L., Lipp, J. S., Schröder, J. M., and Hinrichs, K.-U.: Application of two new LC-ESI-MS methods for improved detection of intact polar lipids (IPLs) in environmental samples, Org. Geochem., 59, 10-21, 2013.

Wright, J. J., Konwar, K. M., and Hallam, S. J: Microbial ecology of expanding oxygen minimum zones, Nat. Rev. Microbiol., 10, 381-394, 2012.

Xie, S., Liu, X.-L., Schubotz, F., Wakeham, S. G., and Hinrichs, K.U.: Distribution of glcerol ether lipids in the oxygen minimum zone of the Easter Tropical North Pacific Ocean, Org. Geochem., 71, 60-71, 2014. 
Yao, M., Elling, F. J., Jones, C., Nomosatryo, S., Long, C. P., Crowe, S. A., Antoniewicz, M. R., Hinrichs, K.-U., and Maresca, J. A.: Heterotrophic bacteria from an extremely phosphate-poor lake have conditionally reduced phosphorus demand and utilize diverse sources of phosphorus, Environ. Microbiol., 18, 656-667, 2015.

Zhang, Y.-M. and Rock, C. O.: Membrane lipid homeostasis in bacteria, Nat. Rev. Microbiol., 6, 222-233, 2008.
Zhu, C., Wakeham, S. G., Elling, F. J., Basse, A., Mollenhauer, G., Versteegh, G. J. M., Könneke, M., and Hinrichs, K.-U.: Stratification of archaeal membrane lipids in the ocean and implications for adaptation and chemotaxonomy of planktonic archaea, Environ. Microbiol., 18, 4324-4336, 2016. 